\title{
Research Paper \\ Comparison of the Effectiveness of Resilience Training and Self-compassion Training on the General Health and Academic Burnout in Students with Depression Symptoms
}

\author{
Babak Noroozi ${ }^{1}$, Ozra Ghaffari Nouran ${ }^{* 2}$, Abbas Abolghasemi ${ }^{3}$, Tavakkol Mousazadeh ${ }^{2}$ \\ 1. Ph.D. Student of Psychology, Department of Psychology, Ardabil Branch, Islamic Azad University, Ardabil, Iran \\ 2. Assistant Professor, Department of Psychology, Ardabil Branch, Islamic Azad University, Ardabil, Iran \\ 3. Professor, Department of Psychology, Faculty of Literature and Humanities, University of Guilan, Rasht, Iran
}

Citation: Noroozi B, Ghaffari Nouran O, Abolghasemi A, Mousazadeh

T. Comparison of the effectiveness of resilience training and selfcompassion training on the general health and academic burnout in students with depression symptoms. J Child Ment Health. 2021; 7 (4) :19-38.

URL: $\underline{\text { http://childmentalhealth.ir/article-1-959-en.html }}$
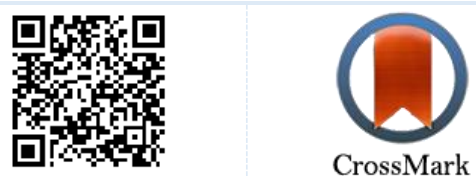

$10.52547 / \mathrm{jcmh} \cdot 7.4 .2$

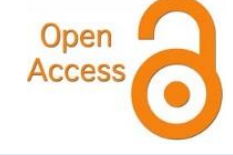

20.1001.1.24233552.1399.7.4.2.0

\section{A R T I C L E I N F O}

Keywords:
Resilience,
self-compassion,
general health,
academic burnout,
depression

Received: 2 Feb 2020

Accepted: 22 Nov 2020

Available: 9 Mar 2021

\section{A B S T R A C T}

Background and Purpose: Depression as a common mental disorder can seriously damage the academic procedure and psychological state of the students. This study aimed to compare the effectiveness of resilience training and elf-compassion training on the general health and academic burnout in students with depression symptoms.

Method: This study was a quasi-experimental research with pretest-posttest control group design. The population included all the male students studying at the first cycle of the secondary schools in Parsabad city (Ardabil province) in the academic year 2017-2018 ( $N=2028)$. A sample of 60 students with depression symptoms was selected through multi-stage cluster sampling and randomly assigned to three groups $(\mathrm{n}=20)$. Data were collected by Depression Self-rating Scale (Birleson, 1981), General Health Questionnaire (Goldberg \& Hillier, 1979) and Academic Burnout Questionnaire (Breso', Salanova, \& Schaufeli, 2007) and then analyzed by ANCOVA through using SPSS Version 20.

Results: Data analysis showed that both resilience and self-compassion training were effective in improving the components of general health and reducing the academic burnout in students with depression symptoms $(\mathrm{P} \leq 0.05)$. Also, based on the follow-up test results, resilience training was more effective than self-compassion training in decreasing the academic exhaustion $(\mathrm{P} \leq 0.05)$.

Conclusion: The results showed that both methods used in this study were effective in improving the general health and reducing the academic burnout. However, due to the increase of flexibility and optimism, relisence training was more effective in reducing the academic exhaustion.

* Corresponding author: Ozra Ghaffari Nouran, Assistant Professor, Department of Psychology, Ardabil Branch, Islamic Azad University, Ardabil, Iran.

E-mail: O.ghaffari@iauardabil.ac.ir

Tel: (+98) 4533728702

2476-5740/ (C) 2021 The Authors. This is an open access article under the CC BY-NC-ND license

(https://creativecommons.org/licenses/by-nc-nd/4.0/). 


\section{Extended Abstract}

\section{Introduction}

Adolescence is considered a critical period, during which the individual is faced with different psychological injuries like depression (1). One of the factors influenced by depression is lifestyle which in its turn is associated with mental health (6). Research shows that depression is associated with lower levels of quality of life (QoL) (7). One of the problems in each academic system which may result in the wastage of human resource and huge amount of expenses is academic burnout (9). Burnout refers to tiredness resulting from academic demands (emotional exhaustion), having a pessimistic sense and lack of interest toward academic tasks (cynicism), and feeling of incompetency as a student (inefficacy) (10).

Other constructs related to academic burnout in positive psychology are resilience and selfcompassion. Resilience is a dynamic process wherein individuals display positive adaptive behaviors in facing with experiences of adversity (15). Different researches show that resilience training can reduce burnout $(18,24, \& 25)$. Self-compassion as the other construct of positive psychology involves three main components: self-kindness, common humanity, and mindfulness (26). Research suggests that selfcompassion training can increase QoL (28) and emotional well-being (33) and decrease academic burnout (38). No previous study was found aiming to compare the effectiveness of resilience training and self-compassion training on adolescents with depression symptoms. Accordingly, present study was conducted to compare the effectiveness of resilience training and self-compassion training on QoL and academic burnout in students with depression symptoms.

\section{Method}

This study was a quasi-experimental research with pretest-posttest control group design. The population included all the male students studying at the first cycle of the secondary schools in Parsabad city (Ardabil province) in the academic year 2017-2018 $(\mathrm{N}=2028)$. A sample of 60 students with depression symptoms was selected through multi-stage cluster sampling and randomly assigned to three groups $(n=20)$. Data were collected by Depression Selfrating Scale (39), General Health Questionnaire (42) and Academic Burnout Questionnaire (47). Resilience training used in this research is based on the model of Henderson, Milstein, \& Krovetz (24). Also, the self-compassion training was that designed by Gilbert in 2009, standardized and carried out on adolescents with depression disorder in Iran by Golpoor, Abolghasemi, Ahadi, \& Narimani (28). After selecting the sample and assigning it to the groups, the participants, having been explained the research objectives, were asked to take part in the research. Firstly, all the three groups were asked to complete the General Health Questionnaire and the Academic Burnout Questionnaire. Then, the first and second experimental group received resilience training and self-compassion training, respectively; while the control group underwent no intervention. Training sessions in either of the methods included eight 90-min weekly group sessions, convened by the first author in the secondary schools of Parsabad city (Ardabil province). Upon completion of the training sessions, all the three groups underwent the post-test. Data were analyzed by Multivariate ANCOVA in SPSS-20.

\section{Results}

Table 1-Eng. Shows the mean and standard deviation of the pre-test and post-test scores for any of the components of the research variables, including general health and academic burnout.

Results of table 1-Eng. Show a decrease in the mean score of all the components for both groups at the post-test phase compared to the pre-test stage. To investigate the effect of resilience and selfcompassion on the components of general health, multivariate ANCOVA was used (It is worth mentioning that the assumptions of this test were studied and results showed that the assumptions were not violated at the level of 0.05). Results of Wilks' Lambada to determine the overall group effect on the components of general health showed that the overall group effect was significant $(\mathrm{P}<0.001)$. 
Table1: Descriptive statistics of the components of general health and academic burnout based on the experimental and control groups

\begin{tabular}{|c|c|c|c|c|c|c|c|}
\hline \multirow{2}{*}{ Component } & \multirow{2}{*}{ Phase } & \multicolumn{2}{|c|}{ Control group } & \multicolumn{2}{|c|}{ Resilience training } & \multicolumn{2}{|c|}{ Self-compassion training } \\
\hline & & Mean & SD & Mean & SD & Mean & SD \\
\hline \multirow{2}{*}{ Somatic symptoms } & Pretest & 7.95 & 4.36 & 10.25 & 5.57 & 8.75 & 3.09 \\
\hline & Posttest & 6.10 & 1.02 & 4.80 & 1.01 & 5.05 & 1.10 \\
\hline \multirow{2}{*}{ Anxiety and insomnia } & Pretest & 9.75 & 2.88 & 10.65 & 2.64 & 9.80 & 2.24 \\
\hline & Posttest & 11.05 & 1.64 & 9.45 & 2.31 & 7.35 & 1.31 \\
\hline \multirow{2}{*}{ Social dysfunction } & Pretest & 9.10 & 2.51 & 8.25 & 1.99 & 11.25 & 3.21 \\
\hline & Posttest & 10.05 & 2.66 & 4.60 & 2.23 & 7.80 & 3.41 \\
\hline \multirow{2}{*}{ Depression } & Pretest & 12.30 & 2.87 & 11.70 & 3.89 & 10.65 & 2.23 \\
\hline & Posttest & 11.60 & 2.26 & 7.55 & 1.73 & 8.60 & 1.98 \\
\hline \multirow{2}{*}{ Academic exhaustion } & Pretest & 14.65 & 3.36 & 13.15 & 2.37 & 14.70 & 4.43 \\
\hline & Posttest & 14.10 & 1.55 & 8.65 & 1.60 & 11.70 & 2.18 \\
\hline \multirow{2}{*}{ Academic uninterested } & Pretest & 11.05 & 3.44 & 11.30 & 1.78 & 11.70 & 2.96 \\
\hline & Posttest & 9.60 & 1.72 & 6.65 & 1.46 & 7.40 & 1.50 \\
\hline \multirow{2}{*}{ Academic inefficacy } & Pretest & 17.55 & 2.26 & 16.45 & 1.99 & 16.20 & 2.39 \\
\hline & Posttest & 19.00 & 2.79 & 12.55 & 2.31 & 13.95 & 2.56 \\
\hline
\end{tabular}

Table 2: Results of multivariate ANCOVA and Bonferroni on the components of the general health

\begin{tabular}{|c|c|c|c|c|c|c|c|c|c|}
\hline & \multirow[b]{2}{*}{ Component } & \multirow[b]{2}{*}{ SS } & \multirow[b]{2}{*}{ df } & \multirow[b]{2}{*}{ MS } & \multirow[b]{2}{*}{$\mathbf{F}$} & \multirow[b]{2}{*}{$\mathbf{p}$} & \multicolumn{3}{|c|}{ Bonferroni pairwise comparison } \\
\hline & & & & & & & $\begin{array}{l}\text { Resilience training } \\
\text { and self-compassion } \\
\text { training }\end{array}$ & $\begin{array}{c}\text { Resilience } \\
\text { training and } \\
\text { waiting list } \\
\end{array}$ & $\begin{array}{c}\text { Self-compassion } \\
\text { training and } \\
\text { waiting list } \\
\end{array}$ \\
\hline \multirow{4}{*}{ Group } & Somatic symptoms & 20.316 & 2 & 10.158 & 9.024 & 0.000 & 1 & 0.001 & 0.006 \\
\hline & $\begin{array}{l}\text { Anxiety and } \\
\text { insomnia }\end{array}$ & 84.683 & 2 & 42.342 & 14.338 & 0.000 & 0.136 & 0.005 & 0.000 \\
\hline & Social dysfunction & 213.181 & 2 & 106.591 & 14.608 & 0.000 & 0.122 & 0.000 & 0.018 \\
\hline & Depression & 154.992 & 2 & 77.496 & 20.416 & 0.000 & 1 & 0.000 & 0.000 \\
\hline
\end{tabular}

Results of multivariate ANCOVA in table 2- Eng. show that there was a significant difference between the three groups in terms of somatic symptoms $(\mathrm{F}=9.024, \quad \mathrm{p}=0.000)$, anxiety and insomnia $(\mathrm{F}=14.338, \mathrm{p}=0.000)$, social dysfunction $(\mathrm{F}=14.608$, $\mathrm{p}=0.000)$ and depression $(\mathrm{F}=20.416, \mathrm{p}=0.000)$. Results of Bonferroni pairwise comparison showed that both methods were effective compared to the control group $(\mathrm{p}<0.01)$ and they were equally effective on the components of the general health.
To investigate the effect of resilience and selfcompassion on the components of academic burnout, multivariate ANCOVA was used (It is worth mentioning that the assumptions of this test were studied and results showed that the assumptions were not violated at the level of 0.05). Results of Wilks' Lambada to determine the overall group effect on the components of the academic burnout showed that the overall group effect was significant $(\mathrm{P}<0.001)$.

Table 3: Results of multivariate ANCOVA and Bonferroni on the components of academic burnout

\begin{tabular}{ccccccccccc}
\hline & Component & SS & df & MS & F & p & $\begin{array}{c}\text { Resilience training and } \\
\text { self-compassion } \\
\text { training }\end{array}$ & $\begin{array}{c}\text { Resilience } \\
\text { training and } \\
\text { waiting list }\end{array}$ & $\begin{array}{c}\text { Self- } \\
\text { compassion } \\
\text { training and } \\
\text { waiting list }\end{array}$ \\
\hline \multirow{2}{*}{ Group } & $\begin{array}{c}\text { Academic exhaustion } \\
\text { Academic }\end{array}$ & 258.473 & 2 & 129.237 & 39.975 & 0.000 & 0.000 & 0.000 & 0.001 \\
& $\begin{array}{c}\text { uninterested } \\
\text { Academic inefficacy }\end{array}$ & 84.388 & 2 & 42.194 & 16.318 & 0.000 & 0.478 & 0.000 & 0.000 \\
\hline
\end{tabular}

Results of multivariate ANCOVA in table 3- Eng. show that there was a significant difference between the three groups in terms of academic exhaustion $(\mathrm{F}=39.975, \quad \mathrm{p}=0.000)$, academic uninterested
$(\mathrm{F}=16.318, \mathrm{p}=0.000)$, and academic inefficacy $(\mathrm{F}=29.504, \mathrm{p}=0.000)$. Also, the results of Bonferroni pairwise comparison showed that although both interventions were effective $(\mathrm{p}<0.01)$, resilience 
training was more effective on academic exhaustion $(p<0.01)$ compared to self-compassion training.

\section{Conclusion}

This study aimed to investigate and compare the effectiveness of resilience training and selfcompassion training on the general health and academic burnout in students with depression symptoms. Findings showed that resilience training improves the components of the general health and academic burnout. Results of this study coincide with Zamiri Nejad, Golzari, Borjali, Hojat and Akaberi (18) indicating the effectiveness of resilience training on the reduction of depression; Yaghoubi and Bakhtiari (24) indicating the effect of resilience training on the reduction of academic burnout and its components; and Lanz (25), suggesting the effectiveness of resilience training on the reduction of burnout in university students. In explaining these results, it can be said that resilience training reduces depression through decreasing the feeling of loneliness and hopelessness (18) and it reduces academic burnout through increasing the optimism (24).

Also, results of this study showed that selfcompassion training can improve the components of general health and academic burnout. Findings are supported by Golpoor, Abolghasemi, Ahadi, \& Narimani (28) indicating the effectiveness of selfcompassion training on the improvement of quality of life and its components in depressed students; Bluth $\&$ Eisenlohr-Moul (33), indicating the effectiveness of self-compassion on the emotional well-being of adolescents; Karami, Sharifi, Nikkhah \& Ghazanfari (38) implying the effectiveness of self-compassionate training on the reduction of academic burnout. To explain this study, it can be stated that self- compassion improves the general health through self-kindness, common humanity, and mindfulness (28) and reduces the academic burnout (9). Results of comparing the effectiveness of resilience training and self-compassion training on the components of general health and academic burnout suggested that resilience training was more effective than selfcompassion training in reducing the academic burnout. No previous study aiming to compare these two training methods was found. To explain this finding, it can be said that resilience training was more effective on reducing the academic burnout due to the increase of flexibility and optimism. The impossibility of implementing the follow-up stage was one of the limitations of the research. Finally, it is suggested that resilience training can be used by school counselors to decrease the academic burnout in students with depression symptoms.

\section{Ethical Considerations}

Compliance with ethical guidelines: This article is extracted from the Ph.D. dissertation of the first author, which was approved under No. 11920705962013 in the Psychology Department, Ardabil Branch, Islamic Azad University with the proposal approval date of 03.03.2018. The permission for its being carried out on the participants was issued by Parsabad Education Administration in 2017. Ethical considerations like gaining the informed consent of the participants and the confidentiality were observed in this research.

Funding: This study was conducted as a Ph.D. thesis with no financial support.

The role of each of the authors: The first author was the senior author, the second and third ones were the supervisors and the forth one was the advisor.

Conflict of interest: There is no conflict of interest in this study.

Acknowledgments: We would like to appreciate the supervisors, the advisor, the participants, and the authorities of Parsabad Education Administration (Ardabil province) as well as the educationists and school consultants. 


\section{مقايسه اثربخشى آموزشهاى تابآورى و شفقت به خود بر سلامت عمومى و فرسودكى تحصيلى داش آموزان با علائم افسردىى}

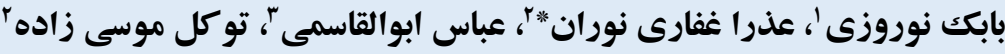

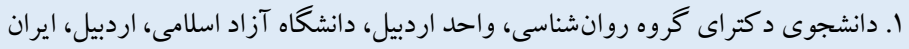

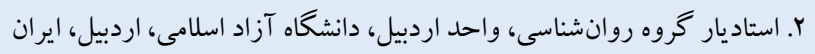

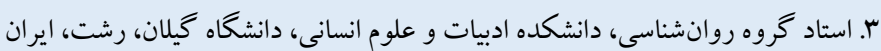

\section{جكيله}

زمينه و هدف: افسردگى به عنوان اختلال روانى رايج مى تواند فرايند تحصيلى و روانشناختى دانش آموزان را با آسيب جدى مواجه كند.

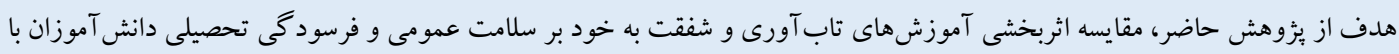

$$
\text { علائم افسردگى بود. }
$$

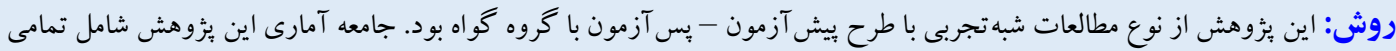

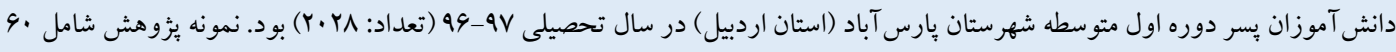

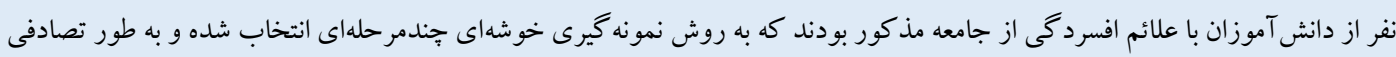

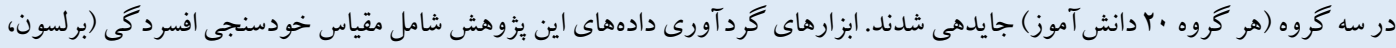

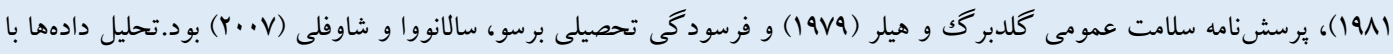

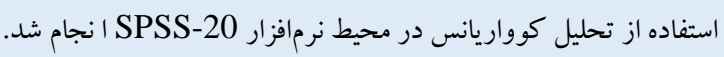

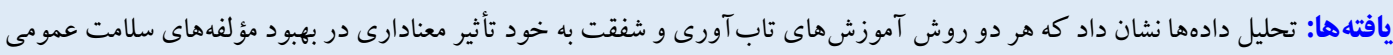

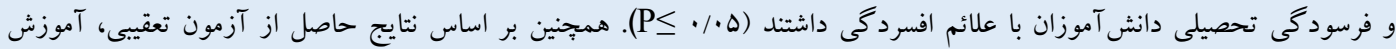

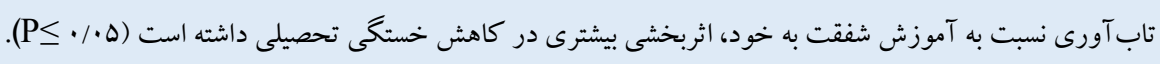

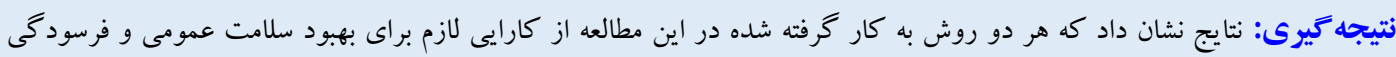

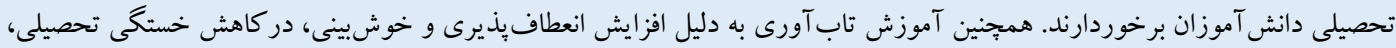

$$
\text { مؤثرتر بوده است. }
$$

مشخصات مقاله

كليدوازهها: تاب آورى، شفقت به خود، أبه، سلامت عمومى،

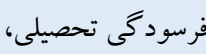
افسردگ

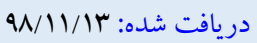

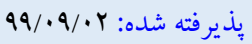
منتشر شده: 99/1Y/19 (

* نويسنده مسئول: عذرا غفارى نوران، استاديار گروه روانشناسى، واحد اردبيل، دانشگاه آزاد اسلامى، اردبيل، ايران.

راياناهם: O.ghaffari@iauardabil.ac.ir 


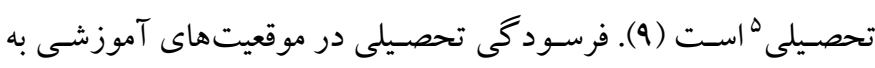

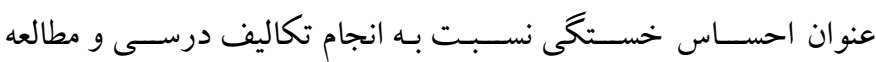

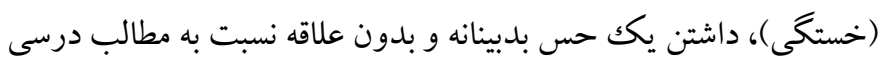

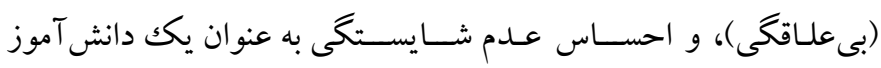

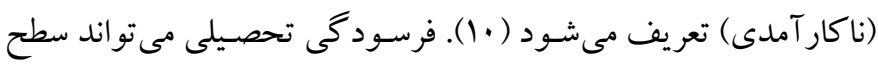
انرزى لازم براى انجام وظايف شــناختى همراه با يادگيرى و همجينين

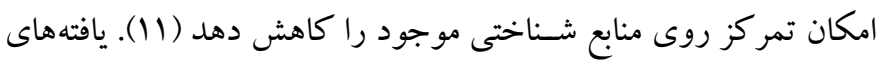

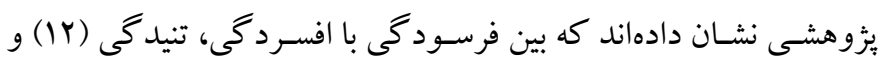
افت تحصيلى، رابطه مثبت و معنادار وجود دارد (س) (I).

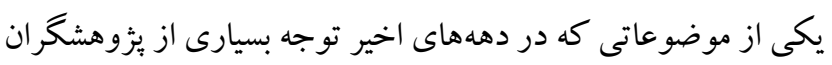

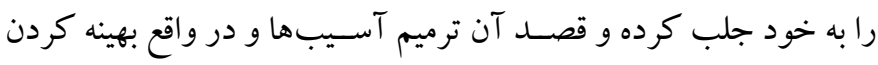

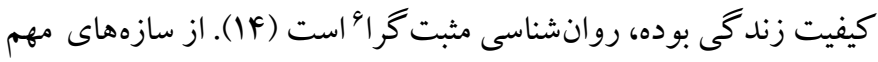

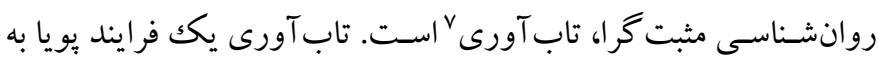

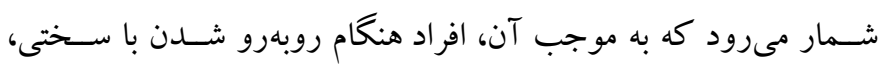
رفتـارهـاى مثبـت ســازش يـافتهترى از خود بروز مى دهند؛ به به عبارتى

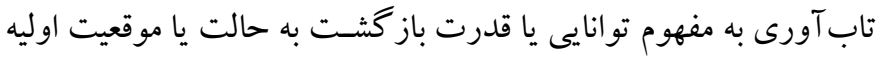

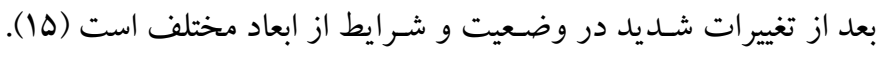
افر ادى تابآور محسوب مى شـوند كه با وجود اينكه سازش يافتكى آنها

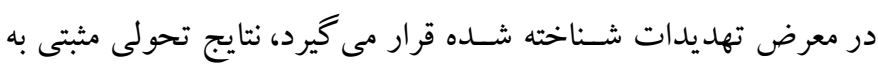

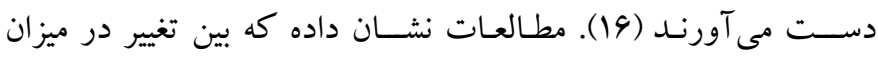

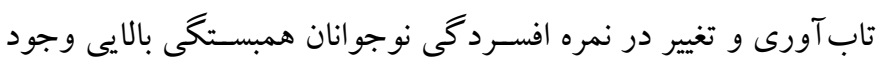

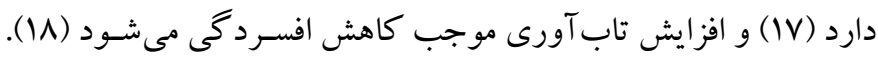

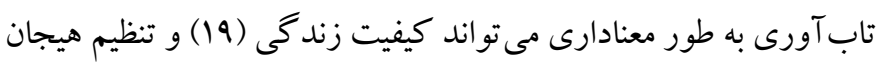

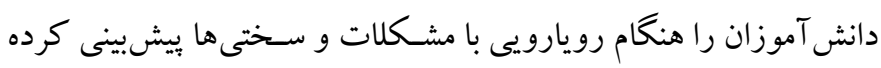

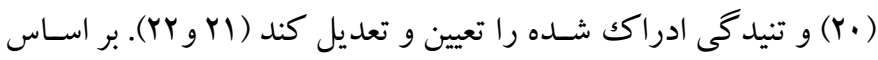

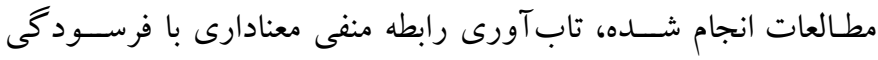

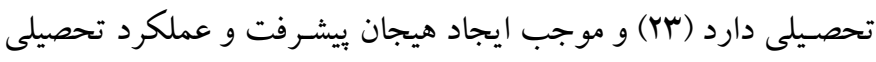

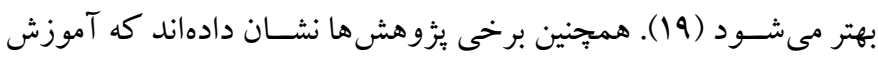
تاب آورى باعث كاهش فرسود

5. Academic burnout 6. Positive psychology 7. Resilience
مقلهمه

نوجوانى دورهاى بحرانى تلقى مىشـــود كـه فرد در طى اين دوره بـاــا

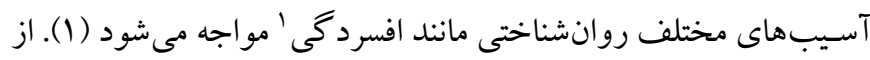

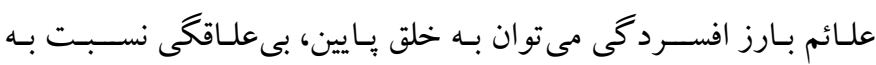

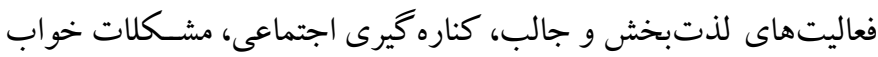

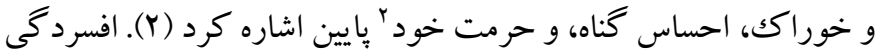
در نوجوانى نه تنها با عملكرد تحصسيلى، اجتماعى، و هيجانى فرد تداخل

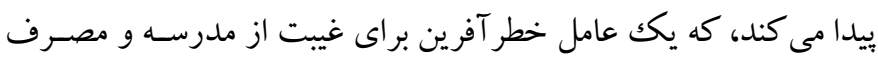

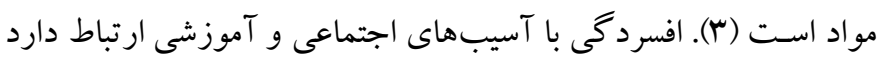

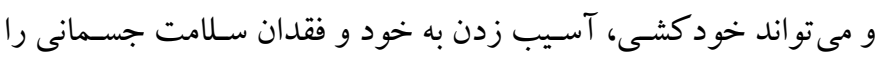
ييشبينى كند (F).

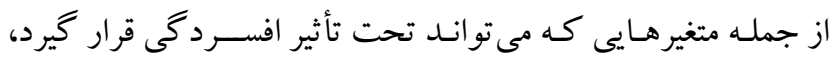

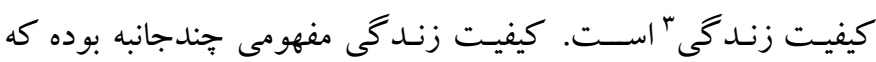

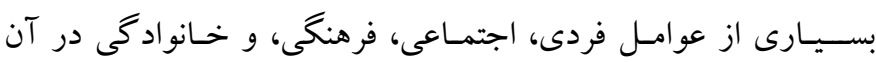

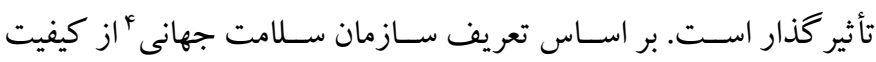

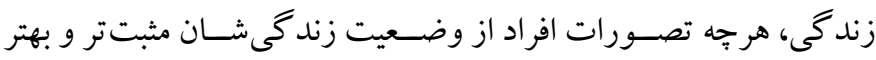

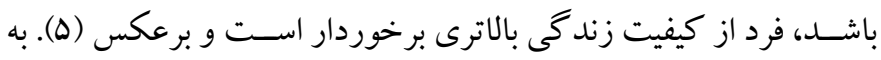

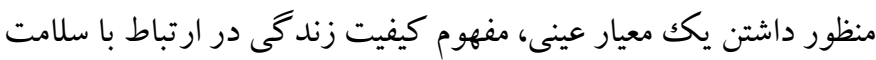

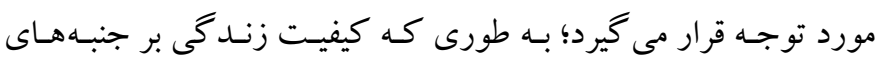

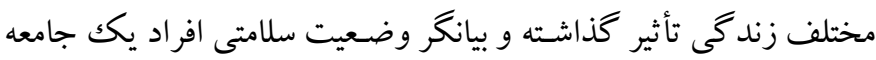

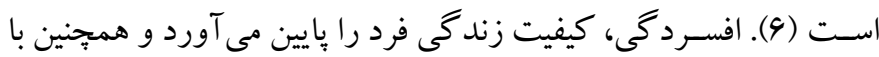

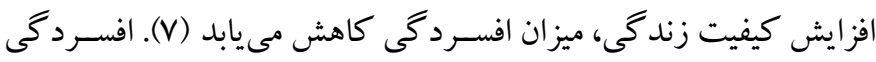

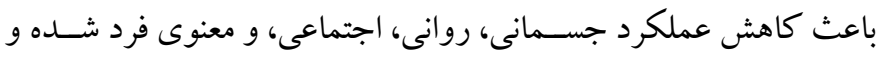
در نتيجه كـاهش رضــايست و كيفيـت زندگى آنها را به دنبال دارد (A). همجِنين اين اختلال روانى بر تفكر، هيجان، و رفتار فرد تأثير منفى دارد و

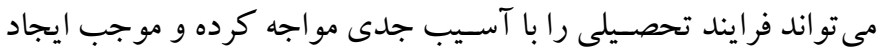

$$
\text { مشكلات تحصيلى در دانش آموزان شود. }
$$

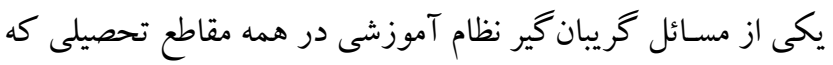

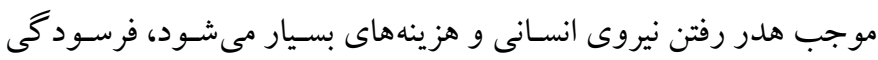

1. Depression

2. Self esteem

3. Quality of life

4. Word Health Organization 
آمارى اين يُزوهش را دانش آموزان بِسـر دوره اول متوســهه با علائم

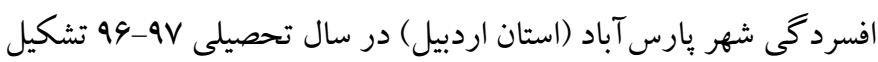

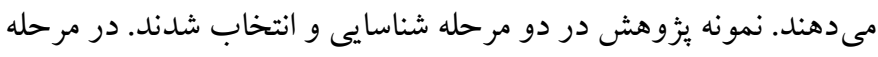

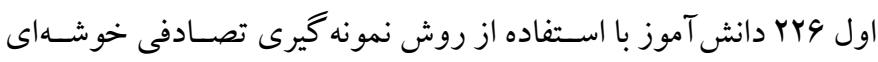
جند مرحلهاى، از جامعه آمارى مذكور انتخاب شدهاند. بدين ترتيب كه، ابتدا از بين ·ل مدرسه پير انه دوره اول متوسطه، F مدرسه و از هر مدرسه r كلاس (يايه هشتم و نهم) به صسورت تصادفى انتخاب شدند. در مرحله

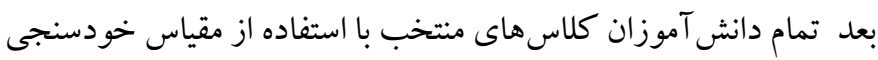

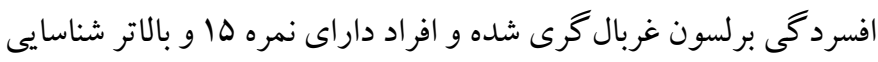

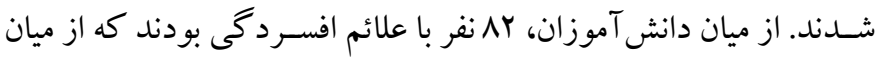
آنها، •9 نفر بر اسـاس مصاحبه بالينى به عمل آمده از طرف ئزوهشكر و

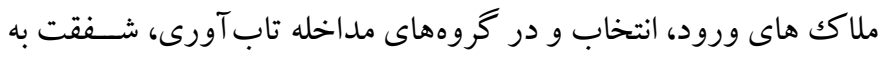

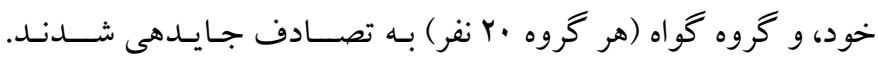

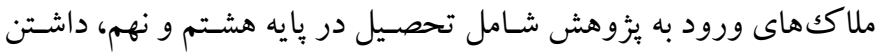

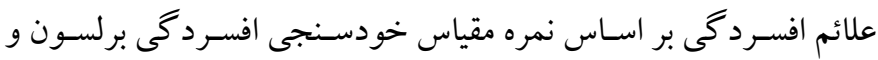

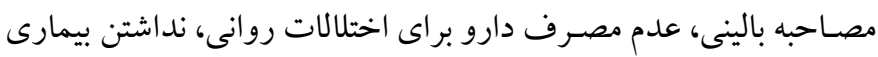

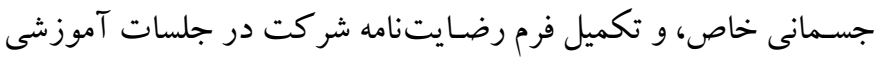
بود. همجنين ملاككهـاى خروج شـامل غيبت بيش از دو جلســه (عدم

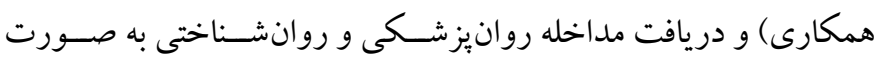

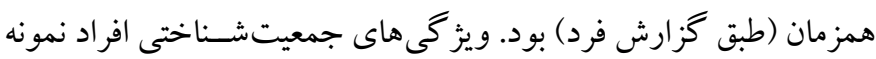

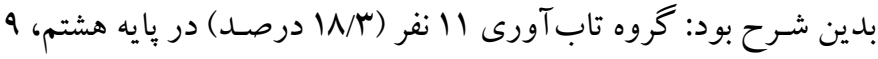
نفر (ها درصـد) در يايه نهم؛ در كروه شفقت به خود با ا نفر (·rدرصد)

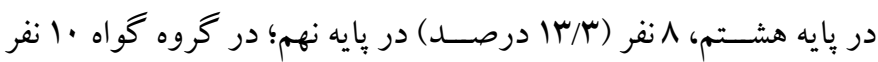
(19/V)

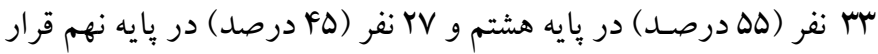

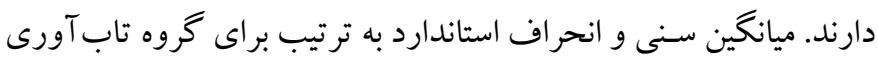
(F/90)

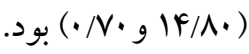

5. Quasi-experimental

6. Pretest-posttest control group design
يكى ديخر از سـازهاى روانشناسى مثبت گرا، شفقت به خود' است.

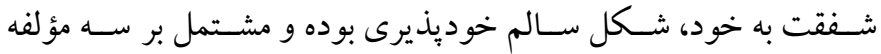

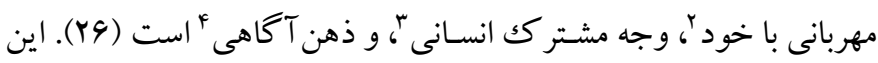

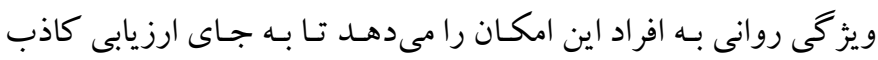

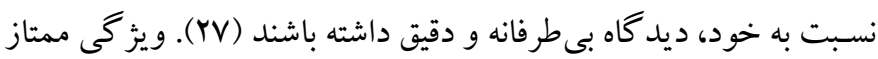
شفقت به خود آن است كه به سمت درد و رنج شخصى فرد جهت داده

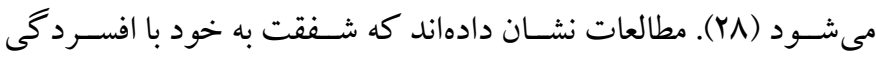

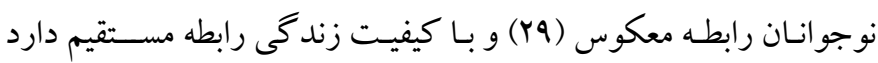

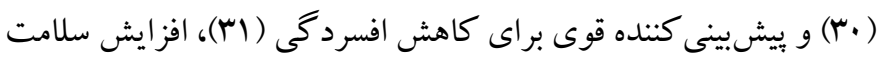

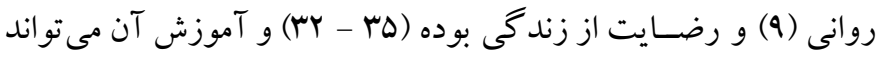

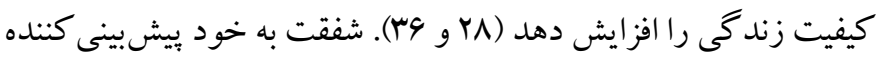

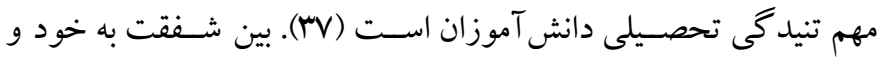

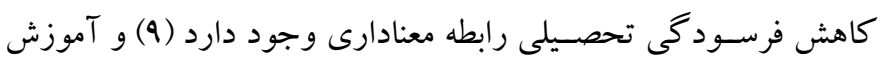
شفقت به خود موجب كاهش فرسودگى تحصيلى دانش آموزان مى شود

حال با توجه به آسيبـهاى روانشـناختى و تحصسيلى در نوجوانان با علائم افسـردگى، به كار گيرى آموزش روانشــناختى مناسـب برواى اين

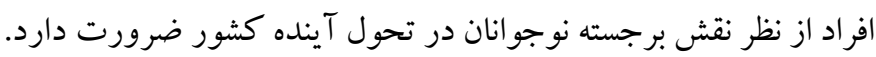

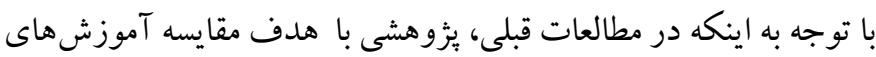

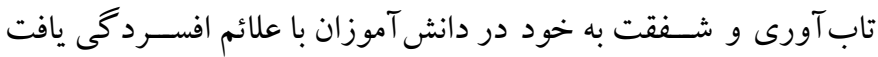

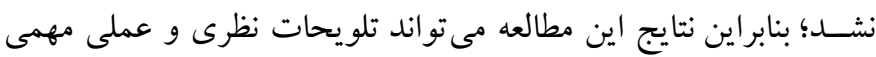

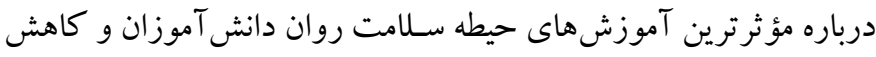

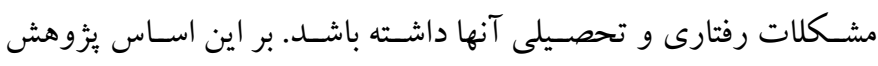
حاضـر با هدف مقايسهـ و تعيين اثربخشسى اين دو شسيوه مداخله بر بهبود

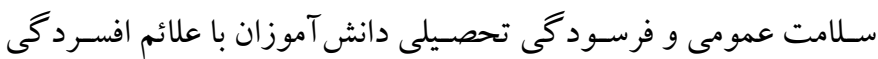
انجام شد.

روش

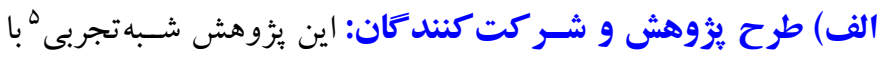

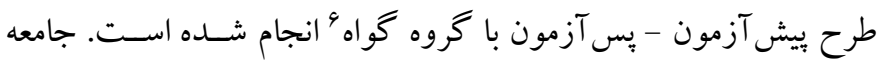

1. Self-compassion

2. Self-kindness

3. Common humanity

4. Mindfulness 
جسـمـانى 9V/، اضـطر اب و بـ خوابى اV/•، اختلال عملكرد اجتماعى

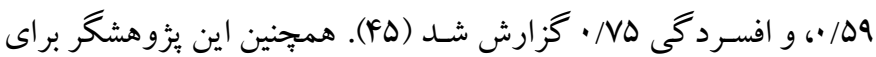

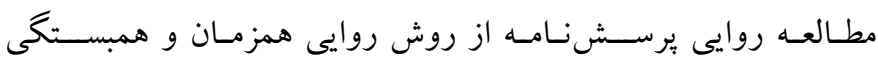

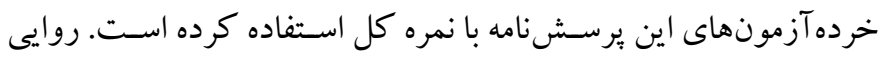

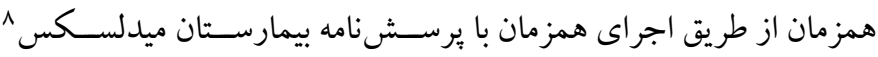

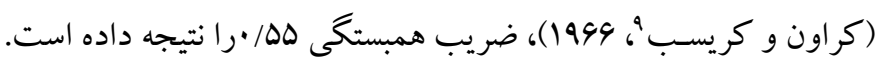

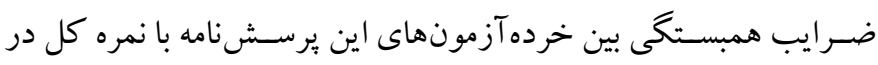

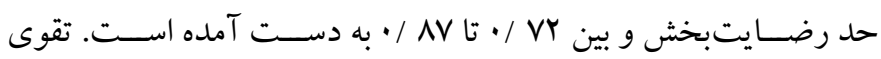

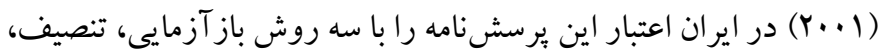

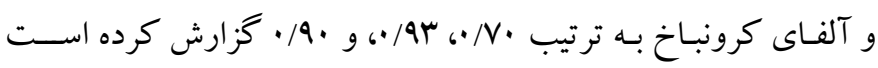

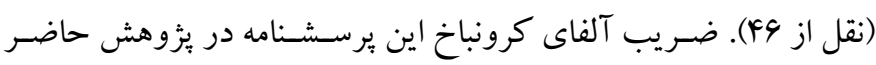

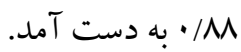

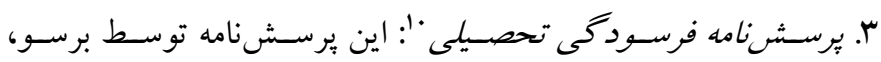

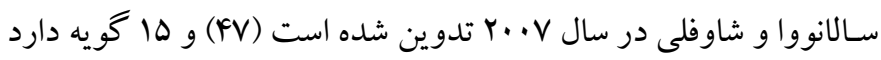
كـه در مقيـاس ينج درجـهاى ليكرت (ازكاملاً مخالفم تا كاملاً موافقم)

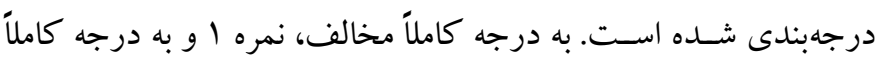

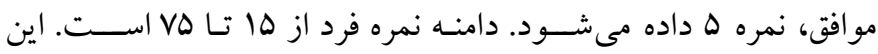

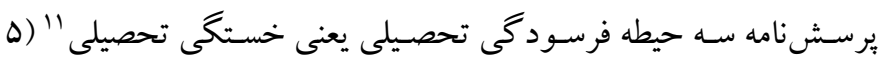

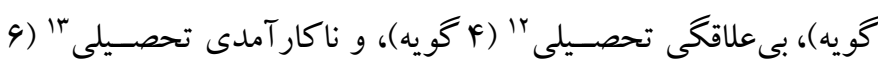

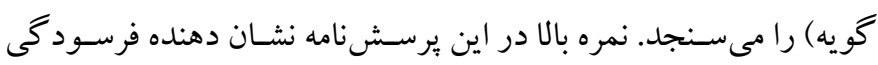

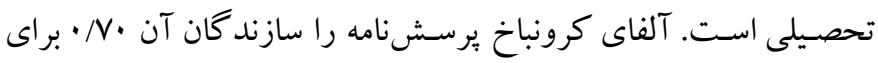

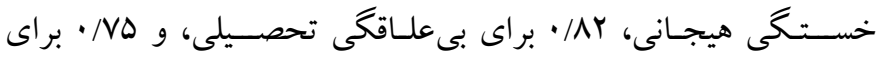

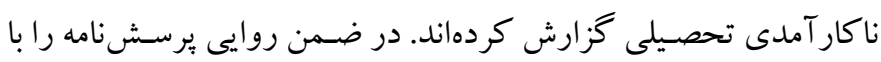

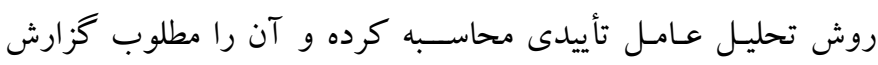

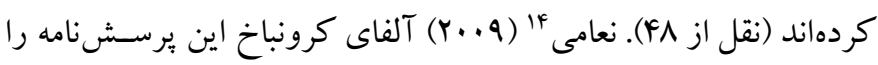

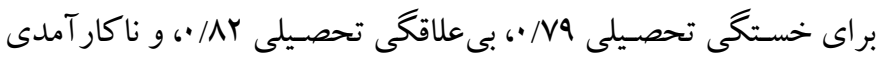

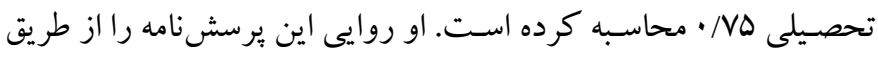

8. Middlesex Hospital Questionnaire (M.H.Q)

\section{Crown \& Crisp}

10. Academic burnout questionnaire

11. Academic exhaustion

12. Academic uninterested

13. Academic inefficacy

14. Naami
ب) (بزار

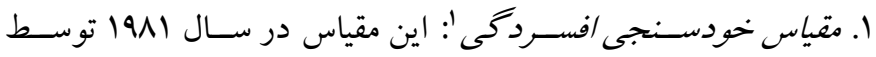

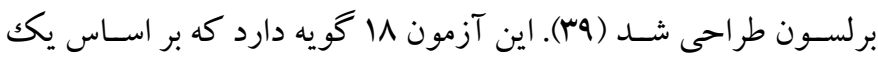

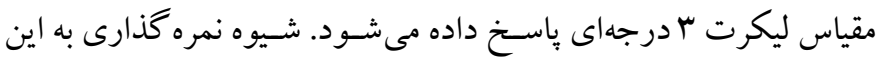

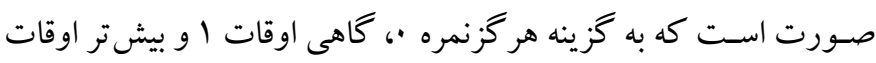
r تعلق مى گيرد. نمره گذارى در گ

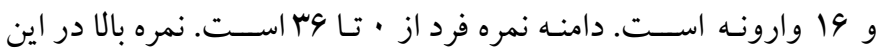

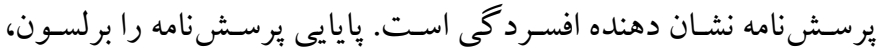

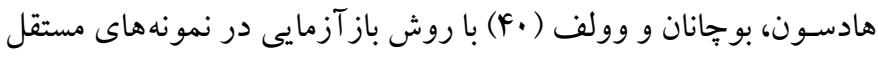

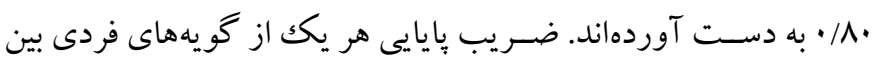

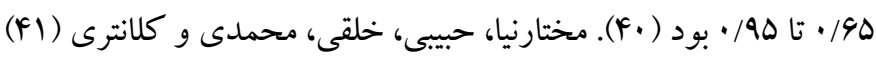

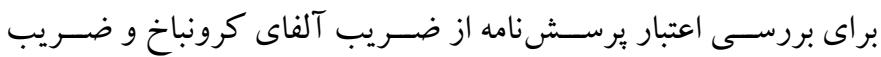

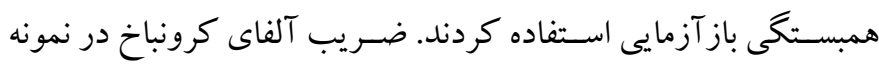
VQVAF

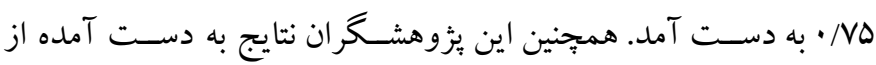

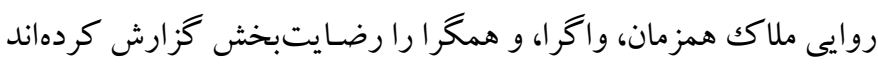

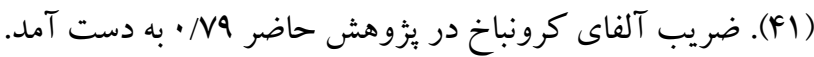

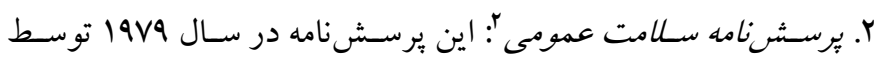

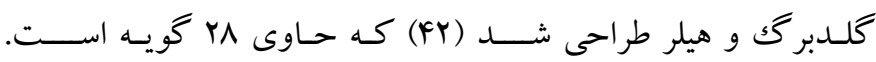

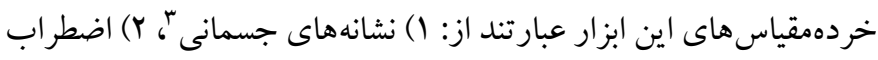

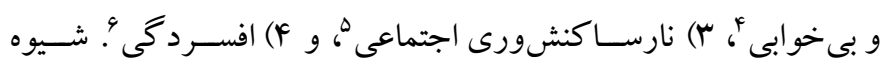

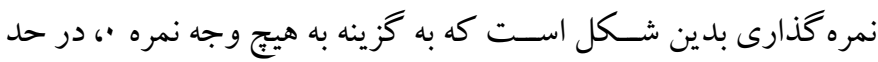
معمول نمره ا، بيش از حـد معمول نمره rا، و خيلى بيشـتر از حد معمول

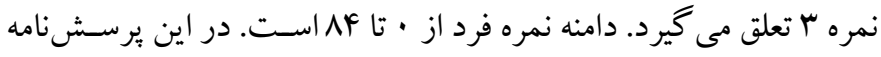

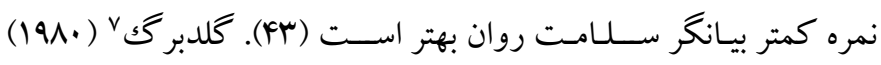

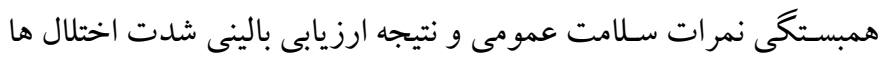

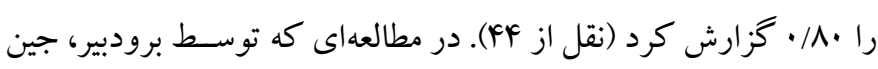

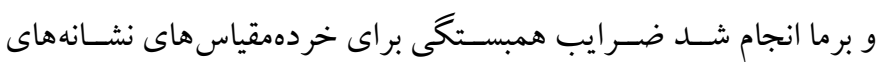

1. Depression Self-Rating Scale (DSRS)

2. General Health Questionnaire (GHQ)

3. Somatic symptoms

4. Anxiety and insomnia

5. Social dysfunction

6. Depression

7. Goldberg 
ابوالقاسمى، احدى و نريمانى (YN) استاندارد شده و روى گروه نوجوانان

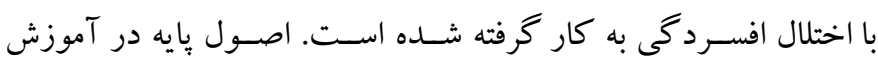

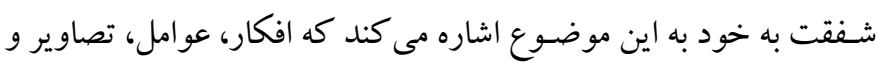

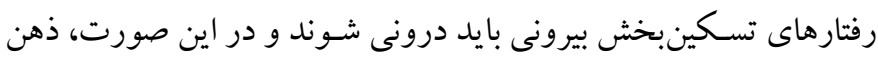

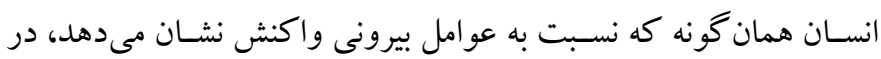

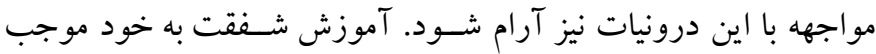
افزايش توان مقابلهاى افراد با آشفتكىها و تمايلات خودانتقادى مى رشوده،

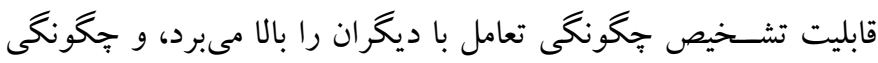

سرو كار داشتن با هيجانات را به روشى روشن فراهم مى كند (YN).

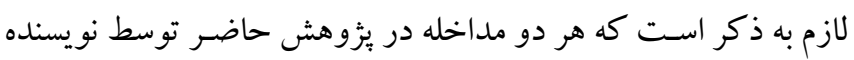

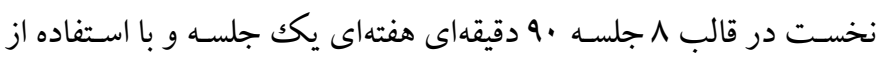

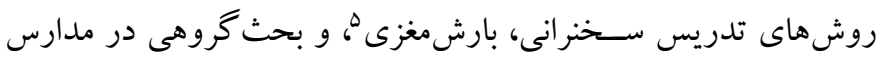

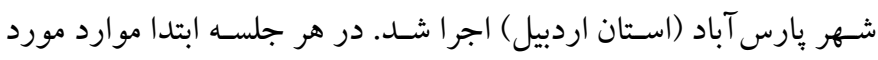
بحث مشـص مى شـد، مهارتهاى جديد به دانش آموزان آموزش داده شـده و تكاليفى براى اجرا در فاصـله بين جلسـات معين مى شـــــ همجنين دانش آموزان موظف بودند تكاليف تعيين شـده در خانه را انجام داده و در هر جلسـه، گزارشـى از روند انجام آن تكليف را بيان كنند و اخر

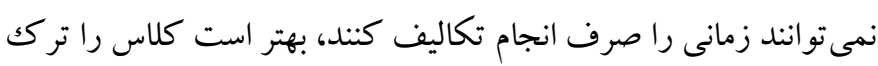

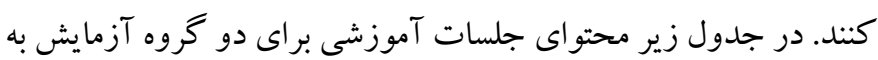
اختصار ارائه شده است.
محاسبه همبستخى آن با برسـشنامه عوامل تنشـخر دانشجويى' (يولادى

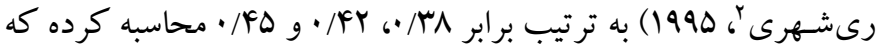

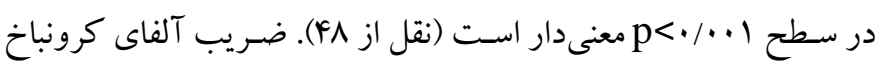
اين يرسشنامه در يثزوهش حاضر M M/ • به دست آمد.

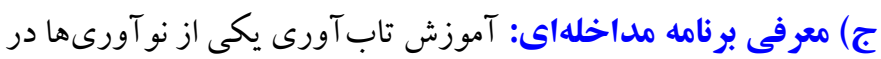

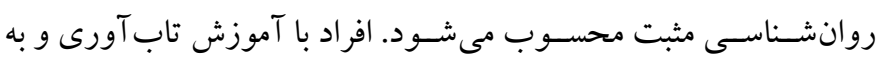

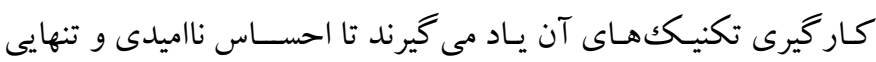

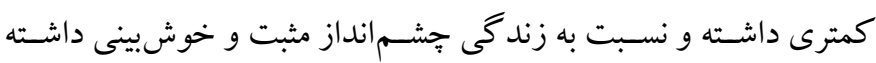

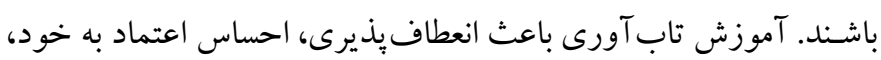

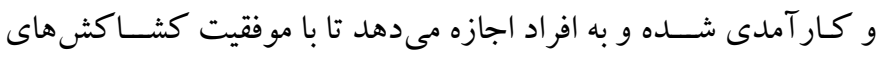

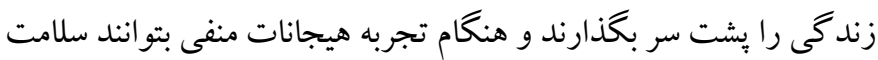

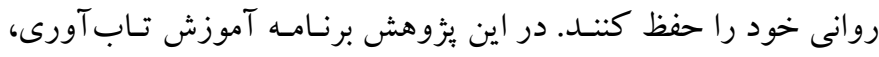

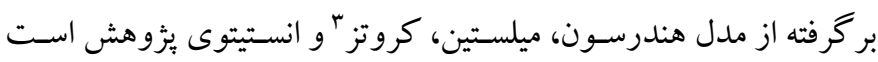

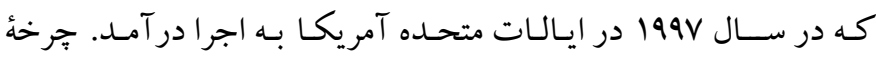

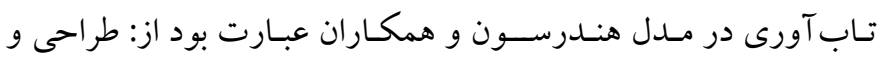

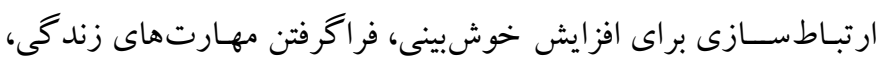

$$
\text { داشتن دلبستخى هاى مثبت، و...(YF). }
$$

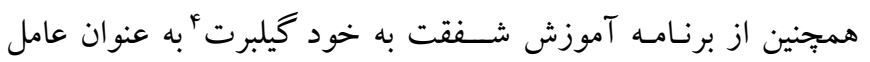

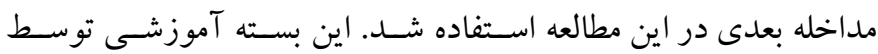

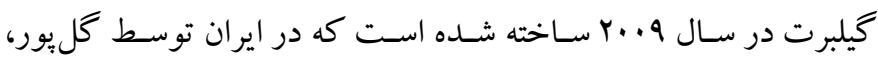

جدول ا: محتواى جلسات آموزش تابآورى و آموزش شفقت به خود

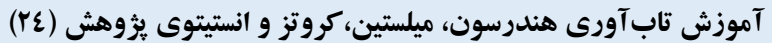

جلسه

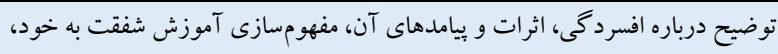

$$
\text { و ارزيابى توسط يرسش ونامهها }
$$

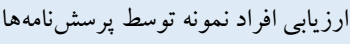

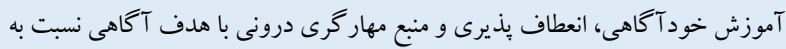

آموزش همدلى: آموزش داده شد كه جֶگونه امور را با نخرش همدلانه دنبال كنند.

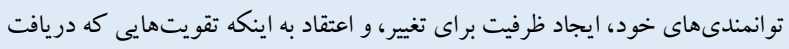

$$
\text { مى كنند حاصل ويز گیى هاى خود آنهاست. }
$$

آموزش بخشايش: يذيرش اشتباهات و بخشيدن خود به خاطر اشتباهات براى سرعت

$$
\text { بخشيدن به ايجاد تغييرات. }
$$

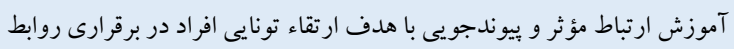

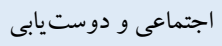

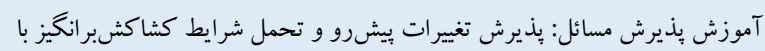

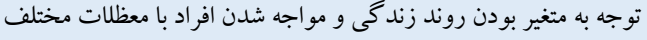

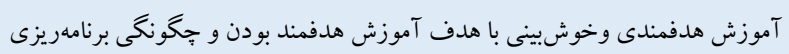
براى دست يابى به اهداف و مثبت انديشى و اميدوارى نسبت به هد آينده.
4. Gilbert self-compassion training

5. Brain Storming
1. Students Stressors Questionnaire (SSQ)

2. Pooladi Rayshahri

3. Henderson, Milstein, Krovetz \& Research Institute Resilience Training 
آموزش رشد احساسات ارزشمند و متعالى: ايجاد احساسات ارزشمند در خود تا بتواند برخورد مناسب و كار آمدى با محيط داشته باشند.

آموزش ذهن آكاهى: ذهن آكاهى همراه با تمرين تنفس، وارسى و لمس بدن و تمركز بر شىء آموزش داده شد.

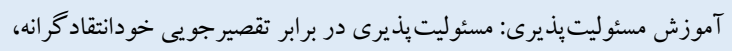

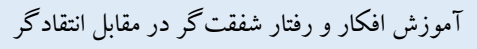

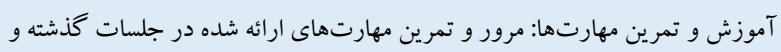

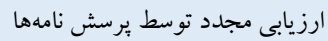

آموزش حل مسئله، تصميم گيرى و مسئوليتيذيرى با هدف آموزش مراحل ينج گانه

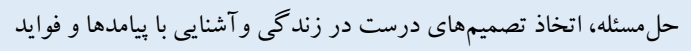

$$
\text { مسئوليتيذيرى. }
$$

آموزش مهار هيجانات با هدف مديريت خشم، اضطر اب و تنيدگى

آموزش حرمت خود و اعتماد به خود با هدف تقويت حرمت خود و اعتماد به خود

آموزش و تمرين مهارتها، مرور و تمرين مهارتهاى ارائه شده در جلسات گذشته، و

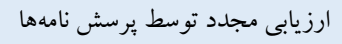

\section{يافتهها}

براى آزمون اينكه آيا گروهها از نظر توزيع بايه تحصسيلى برابر هسـتند يا

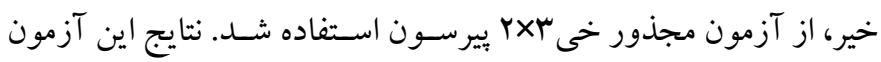

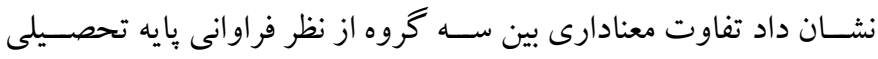

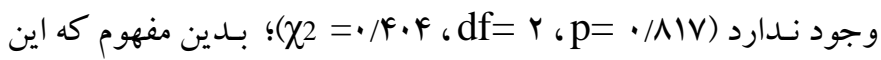

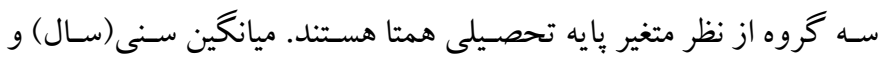

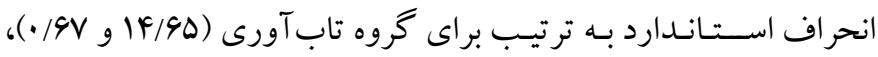

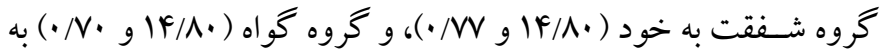
دست آمد. نتايج تحليل واريانس يككراهه مقادير سن سه گرووه نشان داد

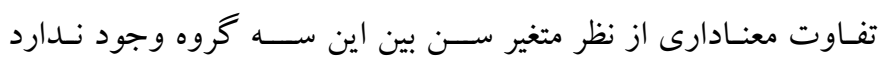

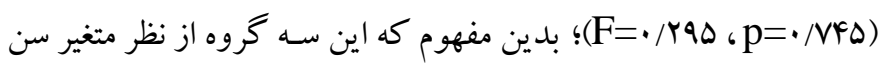

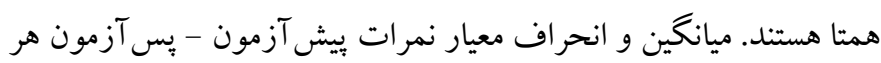

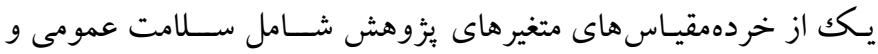

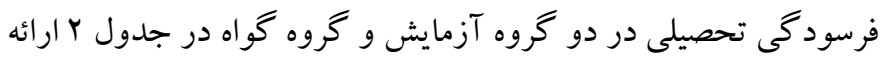

د) روش اجر ا: بعـد از اخـذ مجوزهـاى للازم جهت انجام ئزوهش، افراد

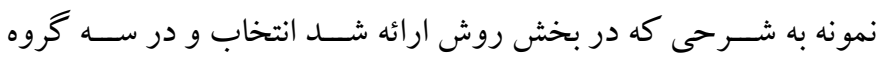

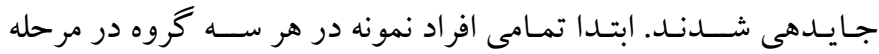

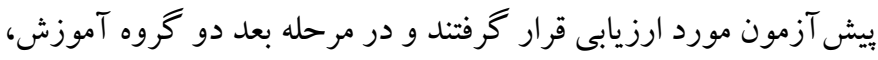

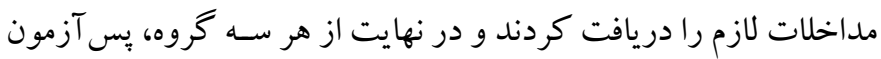

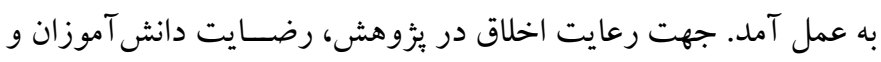
اوليـاى آنها براى شــركت در مطالعه كسـبـ و از تمامى مر احل مداخله

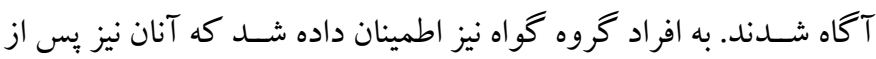

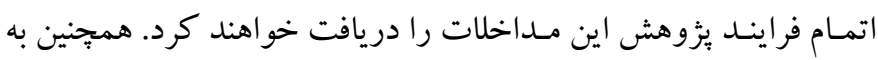

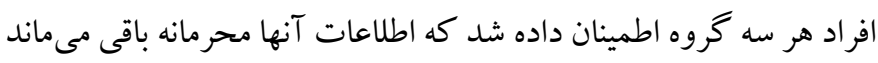

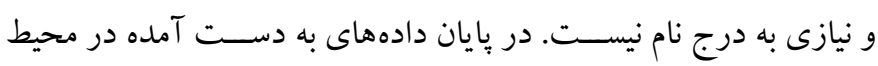

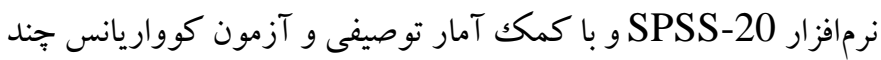
متغيرى تحليل شدند.

$$
\text { شده است. }
$$

\begin{tabular}{|c|c|c|c|c|c|c|}
\hline كشيد & كجى & انحر اف معيار & ميانغين & كروه & مرحله & مؤلفه \\
\hline$-\cdot / \cdot Y V$ & $\cdot /$ TVG & $\Delta / \Delta V$ & $1 . / \% \Delta$ & تاب آورى & & \\
\hline $1 / 191$ & $\cdot|A F|$ & $r / .9$ & $\Lambda / V \Delta$ & شفقت به خود & ييش آزمون & \\
\hline 1/V99 & $1 / \cdot \Delta \Delta$ & $p / r q$ & $\mathrm{~V} / 90$ & كواه & & \\
\hline.$/ 119$ &.$/ .9 V$ & $1 / \cdot 1$ & $F / A$. & تاب آورى & & نشانههاى جسمانى \\
\hline$-\cdot / \Delta \Delta 1$ & $-\cdot / r V r$ & $1 / 1$. & $\Delta / \cdot \Delta$ & شفقت به خود & يس آزمون & \\
\hline$-\cdot / \Delta \wedge 9$ & $-\cdot / r \mid \Lambda$ & $1 / \cdot r$ & $9 / 1$. & كواه & & \\
\hline - - - & $\cdot|q F|$ & $r / 94$ & 1.190 & تابآورى & & \\
\hline$\cdot / 4 \cdot 4$ & $\cdot /$ AVY & $r / Y F$ & $9 / \wedge$. & شفقت به خود & يِيش آزمون & اضطراب و بىخوابى \\
\hline$-\cdot / \Delta \Lambda$ & $\cdot / 41$ & $r / M$ & Q/vD & كواه & & \\
\hline
\end{tabular}

\section{جدول r: شاخصهاى توصيفى مؤلفه هاى سلامت عمومى و فرسود مى تحصيلى به تفكيك تروههاى ثزوهش}




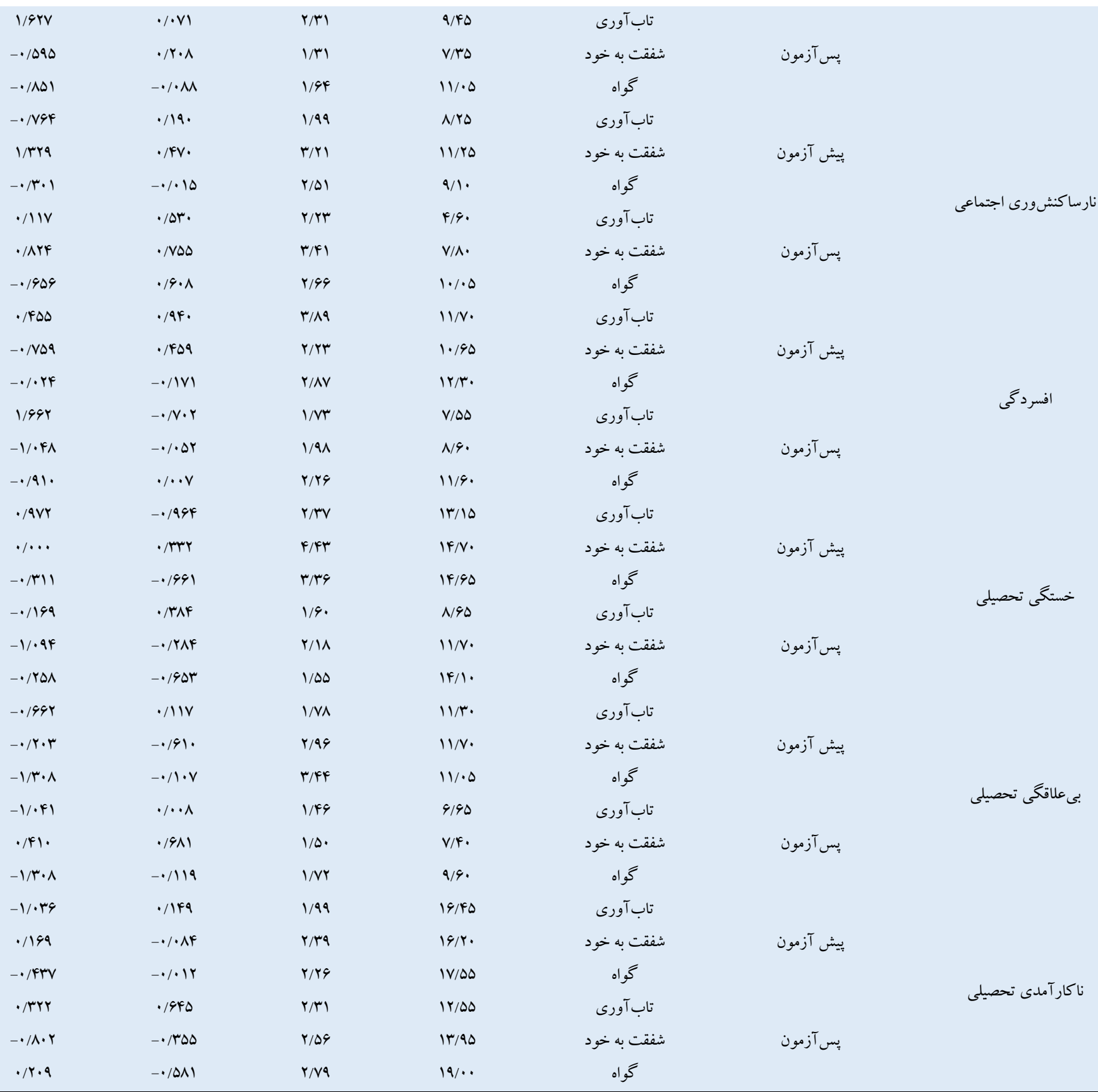

سـلامت عمومى و فرسودگى تحصيلى افراد نمونه از روش آمارى تحليل

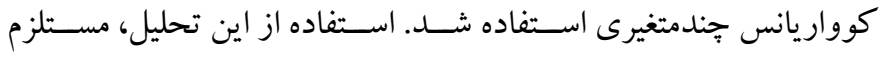
رعايت يِشفرضهايى است كه يِش از اجراى آزمون مورد بررسى قرار كرفتند.

جهـت بررسـى بيشفرض نرمـال بودن دادهها از شــاخص كجى و

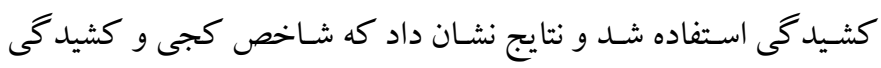

نتايج جدول r نشــان مىدهد كه ميانگين نمرات تمام مؤلفهها در هر دو گروه آموزشـىى، در مرحله يس آزمون نسـبت به مرحله يِيش آزمون

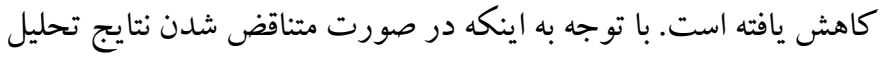

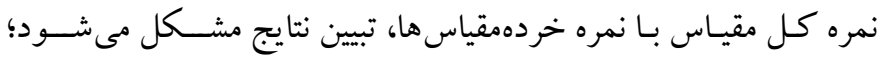

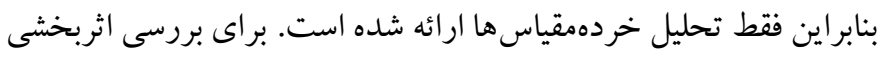

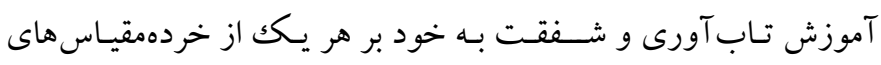




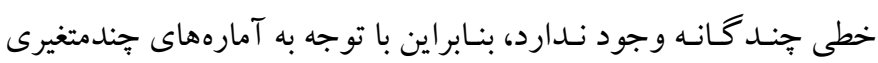

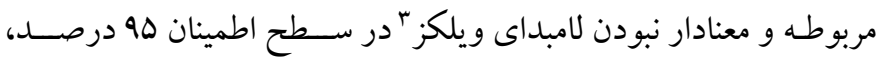
مفروضـه همكنى ضسر ايب ركرسـيون برقرار اسـت. با توجه به برقرارى مفروضــهــاى تحليـل كوواريانس جنـدمتغيرى، مجاز به اســتفاده از اين آزمون آمارى هستيم. براى تعيين اثر كلى متغير كروه بر مؤلفـهـهـاى ســلـامـت عمومى از

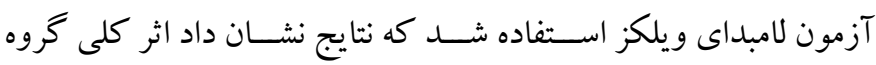

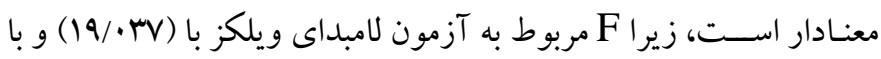

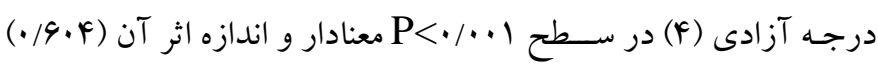
اســت؛ يعنى بين گروههـاى آزمـايش و گروه گواه حسداقـل در يكى از مؤلفـهـهـاى ســـلـامـت عمومى تفاوت معنى دارى وجود دارد. بر اى تعيين اينكـه اين تـأثير كلى در كدام يكك از مؤلفههاى ســلامت عمومى وجود دارد، نتايج تحليل كوواريانس جند متغيرى در جدول ب ارائه شـده است. اطلساعات مربوط به تحليل كوواريانس جندمتغيرى براى بررسـى تفاوت كروههاى آزمايش و كواه از نظر مؤلفههاى سـلامت عمومى (نشـانه ایى جسـمانى، اضـطر اب و بى خوابى، نارساكنشورى اجتماعى، و افسردكى) در جدول ب نشان داده شده است.
همه ســطوح يثزوهش در دامنه Y و Y-قرار داشــت و اين به معناى نرمال بودن دادهها اســت. به منظور بررسـى همكنى واريانس خطاى متغيرهاى يزوهش در كروههـاى آزمايش و كو اه، از آزمون لوين ' اســتفاده شــد. نتايج نشـان از عدم معنى دارى آزمون لوين براى همه ســوح در ســطح

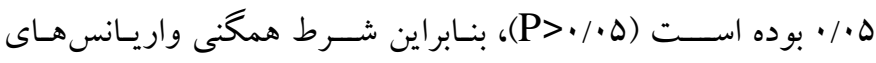
بين گروهى رعـايـت شــده اســت. نتـايج آزمون ام باكس، همخًن بودن مـاتريس كوواريانس متغيرهاى وابســه در تمام ســـوح متغير مســتقل

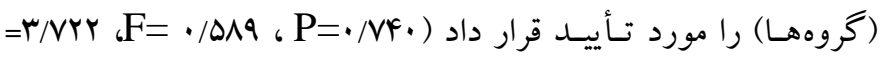
Box's M معنادارى رابطه بين متغيرها نشــان داد كه رابطه بين آنها معنادار اســت

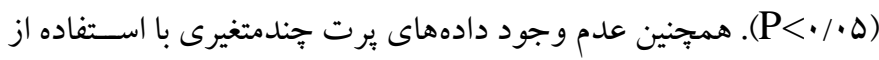
فاصـله ماهالانوبيس ‘ مورد بررسى قرار گرفت كه داده يرت شناسايى نشد و صسحت اين فرضسيه بررسـى شـد. علاوه بر اين هم خطى بين متغيرهاى

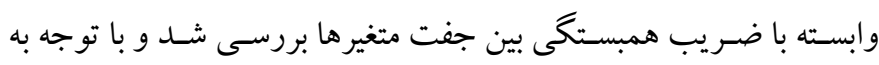
اينكه تمامى ضـرايب همبستخى بين جفت متغيرها در حد متوسط (س/ • تا

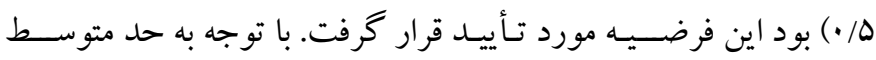

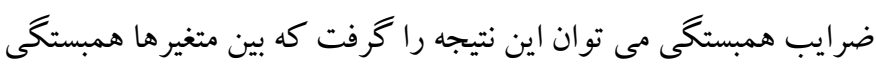

جدول ": نتايج آزمون تحليل كوواريانس جندمتغيرى براى تعيين تفاوت بين كروهى در مؤلفهاى سلامت عمومى

\begin{tabular}{|c|c|c|c|c|c|c|c|c|}
\hline توان آمارى & مجذور اتا & $\mathbf{p}$ & $\mathbf{F}$ & MS & df & SS & مؤلفههاى كيفيت زندكى & \\
\hline$\cdot / M M$ & $\cdot /$ TST &.$/ \cdot 1$ & $r / I \Delta V$ & $r / \Delta \Delta F$ & 4 & $r \mid / r Y I$ & نشانه هاى جسمانى & \multirow{4}{*}{ الكوى تصحيح شده } \\
\hline 1 & $\cdot / 014$ & $\cdot / \cdots$ & $9 / \pi \Delta$ & rV/91Y & 9 & $190 / 9 V \mathrm{~V}$ & اضطراب و بىخوابى & \\
\hline 1 & $\cdot / 4 \wedge \Delta$ & $\% \cdots$ & N/TrI & $9 \cdot / 111$ & 4 & rGF/YGN & نارساكنشورى اجتماعى & \\
\hline 1 & $\cdot / 0 \cdot 4$ & $\cdot / \cdots$ & N/৭৭. & $m q / \cdot 11$ & 4 & $r .4 / .94$ & افسردحى & \\
\hline.$/ 99 \mathrm{~V}$ & $\cdot /$ TAF & $\cdot / \cdots$ & $Q / \cdot Y F$ & $1 \cdot / 1 \Delta \Lambda$ & r & $r \cdot / r 19$ & نشانه هاى جسمانى & \multirow{4}{*}{ 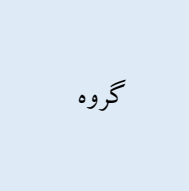 } \\
\hline$\cdot / 991$ & $\cdot / 401$ & $\cdot \cdots$ & $\mid F / T H A$ & FY/MFY & r & $\Lambda F / 9 \wedge r$ & اضطراب و بىخوابى & \\
\hline.$/ 991$ & $\cdot / r \Delta \Delta$ & $\cdot \cdots$ & $1 F / 9 \cdot 1$ & $1.9 / 091$ & r & $r|r / M A|$ & نارساكنشورى اجتماعى & \\
\hline 1 & . / Fro & $\cdot \ldots$ & $r \cdot / 419$ & $V W / 4 a 9$ & r & $1 \Delta F / 9 Q Y$ & افسردگى & \\
\hline
\end{tabular}

همجينين ميز ان اندازه اثر در جدول ب نشـان مىدهد كه عضويت گروهى،

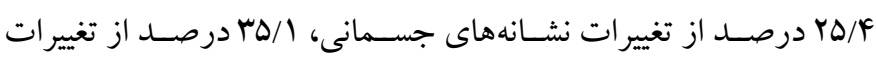
اضطراب و بى خوابى، ه/هس درصد از تغييرات نارسا كنشورى اجتماعى،

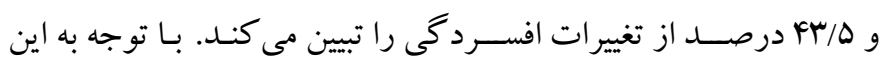

بـا توجه به جدول ب آماره F براى مؤلفههاى نشــانههاى جســمانى

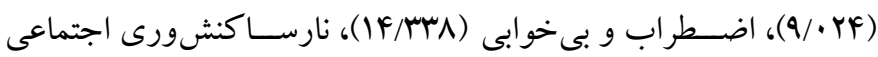
(IF/9·N) مىدهـد بين ســهـ گرووه در اين مؤلفـههـا تفـاوت معنـادارى وجود دارد. 
مؤلفه هاى فرسـودگى تحصسيلى تفاوت معنادارى وجود دارد. براى تعيين اينكه اين تأثير كلى در كدام مؤلفه هاى فرسودگى تحصيلى وجود دارد،

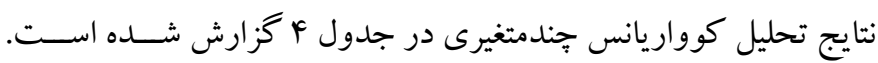
اطلساعات مربوط به تحليل كوواريانس جندمتغيرى براى بررسـى تفاوت

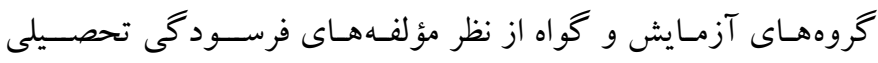
(خســـى تحصـيلى، بى علاقكى تحصـيلى، و ناكار آمدى تحصـيلى) در

$$
\text { جدول F ارائه شده است. }
$$

يـافتهها مى توان كفت كه آموزش تاب آورى و شـفقتت به خود موجب كاهش نشــانه هاى جســمانى، اضـــر اب و بـىخوابى، نارســاكنشورى اجتماعى، و افسردخى دانش آموزان مى شود.

براى تعيين اثر كلى متغير گروه بر مؤلفههاى فرسـودگى تحصسيلى از آزمون لامبداى ويلكز اسـتفاده شــد كه نتايج نشــان داد اثر كلى كروه معنـادار اســت، زيرا F مربوط به آزمون لامبداى ويلكز با (I9/MVA) و با

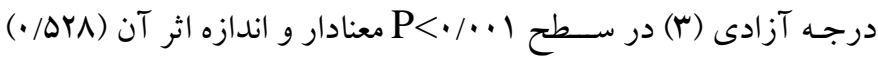

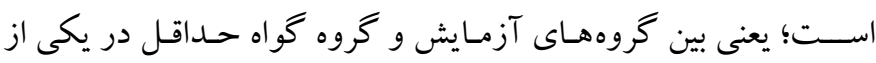

جدول ع: نتايج آزمون تحليل كوواريانس جند متغيرى براى تعيين تفاوت بين كروهى در مؤلفهاى فرسودكى تحصيلى

\begin{tabular}{|c|c|c|c|c|c|c|c|c|}
\hline توان آمارى & مجذور اتا & $\mathbf{p}$ & $\mathbf{F}$ & MS & df & SS & مؤلفههاى فرسودىى تحصيلى & \\
\hline 1 & .1949 & $\cdot / \cdots$ & $19 / \cdot V 9$ & $91 / 911$ & $\Delta$ & $r \cdot N / \mu \cdot \Delta$ & خستكى تحصيلى & \\
\hline.$/ 991$ & $\cdot / 4 \cdot 4$ & $\cdot / \cdots$ & V/rIf & $|N / 91|$ & $\Delta$ & $Q F / \Delta \Delta \Delta$ & بى علاقكى تحصيلى & الخوى تصحيح شده \\
\hline 1 & $\cdot / \Delta \Delta \Delta$ & $\cdot / \cdots$ & $\mid r / F q$. & $9 Y / 9 V F$ & $\Delta$ & KGT/MVY & نا كار آمدى تحصيلى & \\
\hline 1 & $\cdot / 098$ & $\cdot / \cdots$ & rq/qvo & $\mid r Q / r r V$ & r & rDN/FVY & خستخى تحصيلى & \\
\hline.$/ 999$ & $\cdot / r V v$ & $\cdot / \cdots$ & $19 / \pi 11$ & $F Y / l 9 F$ & r & $\Lambda F / r M$ & بىعلاقكى تحصيلى & 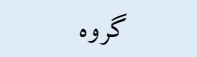 \\
\hline 1 & . $/ \Delta Y Y$ & $\cdot / \cdots$ & $r q / \Delta \cdot F$ & $r \cdot r / 9 \Lambda$. & r & $r \cdot \Delta / r \Delta q$ & نا كار آمدى تحصيلى & \\
\hline
\end{tabular}

درصــد از تغييرات ناكار آمدى تحصـيلى را تبيين مى كند. با توجه به اين

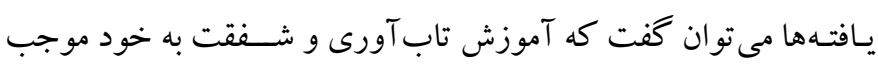
كاهش خستخى تحصسيلى، بى علاقكى تحصسيلى، و ناكار آمدى تحصيلى دانش آموزان مىشـود. در ادامه جهت مقايسه اثربخشى دو نوع مداخله بر متغيرهاى وابسته، از نتايج آزمون تعقيبى بونفرونى ' استفاده شده است كه در جدول ه خزارش شده است.

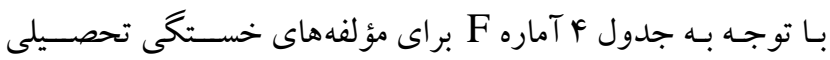

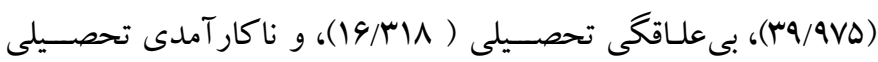

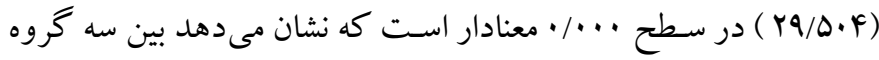
در اين مؤلفهها تفاوت معنادارى وجود دارد. همجينين ميز ان اندازه اثر در

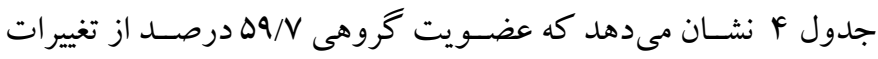
خستخى تحصسيلى، MV/V درصد از تغييرات بى علاقكى تحصيلى، و هY/Y

جدول 0: نتايج مقايسه زوجى مؤلفههاى سلامت عمومى در كروههاى آزمايش

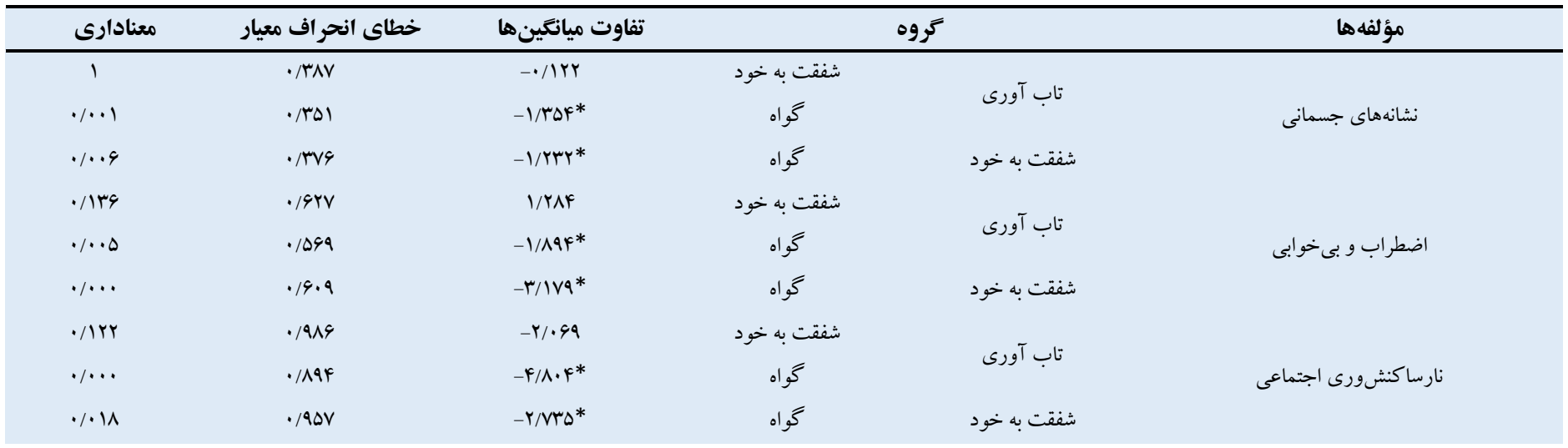




\begin{tabular}{|c|c|c|c|c|}
\hline 1 & $\cdot / \mathrm{VII}$ & $-\cdot / 090$ & شفقت به خود & تاب آو, \\
\hline$\cdot / \cdots$ & .1940 & -r/Arr* & كواه & - \\
\hline $1 \ldots$ & .199. & $-r / r \Delta V^{*}$ & كواه & شفقت به خود \\
\hline
\end{tabular}

افسرد گى آزمودنى ها داشته و به كاهش اين مؤلفهها در آزمودنىها منجر

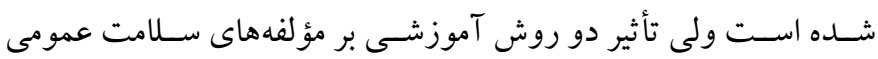

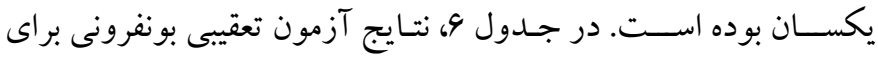

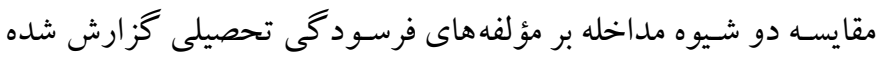

نتايج آزمون بونفرونى در جدول ه نشــان مى دهد كه در مؤلفههاى نشـانهاى جسمانى، اضطر اب و بـىخو ابى، نارسا كنشوروى اجتماعى، و و

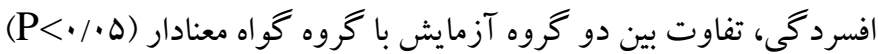

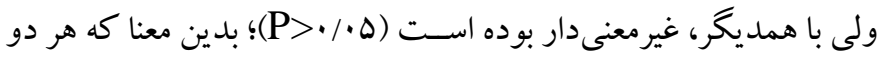

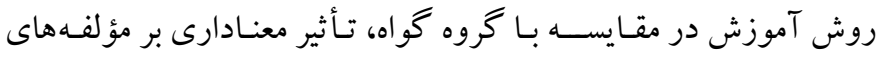

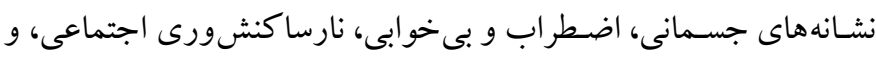

جدول 1: نتايج مقايسه زوجى مؤلفهاى فرسودمى تحصيلى در كروههاى آزمايش

\begin{tabular}{|c|c|c|c|c|c|}
\hline معنادارى & خطاى انحر اف معيار & تفاوت ميانكَينها & & & مؤلفه ها \\
\hline$\cdot / \cdots$ & $\cdot / \Delta \Lambda$. & $-r / 9 r{ }^{\prime} *$ & شفقت به خود & \multirow{2}{*}{ تاب آورى } & \multirow[t]{3}{*}{ خستخى تحصيلى } \\
\hline$\cdot \%$ &.$/ \Delta 9$. & $-\Delta / Y \Delta \Delta *$ & كواه & & \\
\hline.. .1 &.$/ \Delta 9$. & $-Y / T Y I^{*}$ & كواه & شفقت به خود & \\
\hline$\cdot / \mathrm{ava}$ & $\cdot / \Delta 1 \wedge$ & $-\cdot N F$ & شفقت به خود & \multirow{2}{*}{ تاب آورى } & \multirow[t]{3}{*}{ ئعلاقكى تحصيلى } \\
\hline.$\ldots$ & . $/ \Delta \mathrm{YA}$ & $-r / 911 *$ & كواه & & \\
\hline.$\cdots$ & $\cdot / \Delta \mathrm{TV}$ & $-Y / I V r^{*}$ & كواه & شفقت به خود & \\
\hline$\cdot / / 999$ & $\cdot / A F \Delta$ & $-1 / 419$ & شفقت به خود & \multirow{2}{*}{ تاب آورى } & \multirow[t]{3}{*}{ ناكارآمدى تحصيلى } \\
\hline$\cdot \cdots$ & ./A9. & -9/TrR* & كواه & & \\
\hline.$/ \ldots$ & . $/ \triangle \Delta Q 9$ & $-F / q . F *$ & كواه & شفقت به خود & \\
\hline
\end{tabular}

\section{بحث و نتيجه Fيرى}

هدف ئزوهش حاضر مقايسه و تعيين اثربخشى آموزش هاى تاب آورى و و

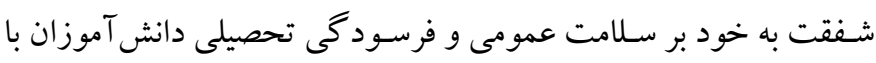

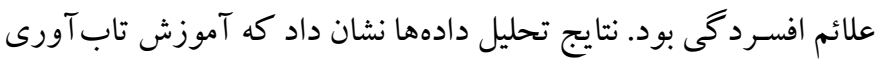
موجب بهبود مؤلفه هاى سـلامت عمومى (نشانه هاى جسمانى، اضطر اب و

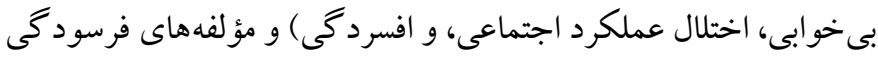

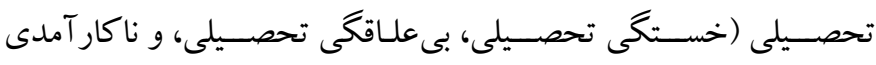

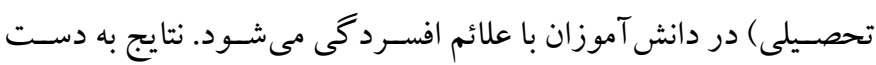

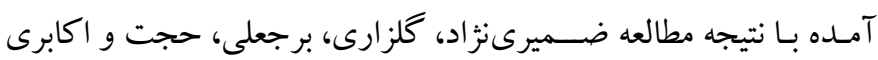

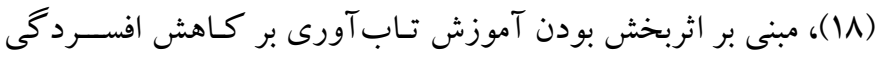

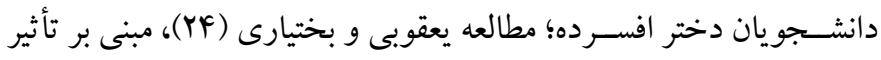

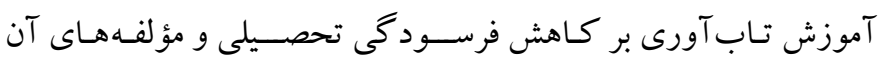

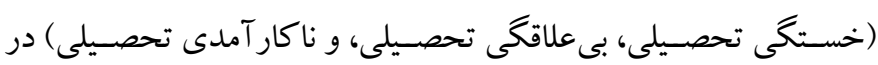

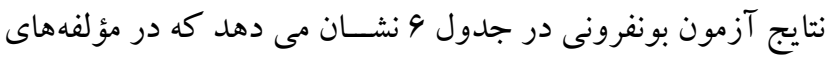

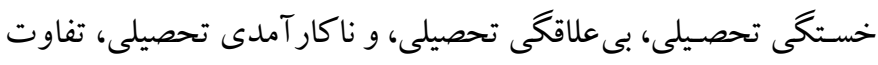

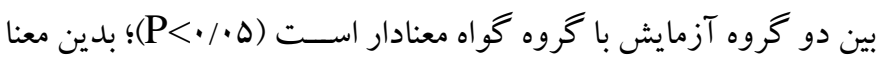

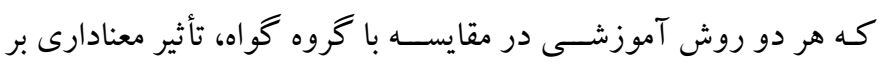

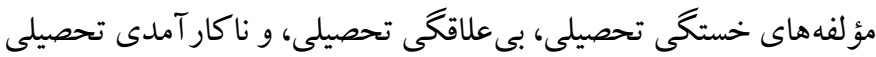

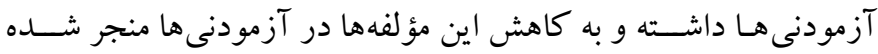

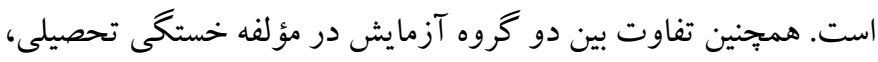

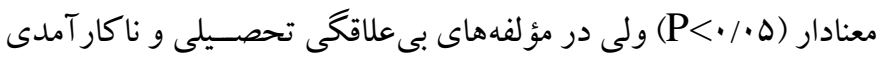

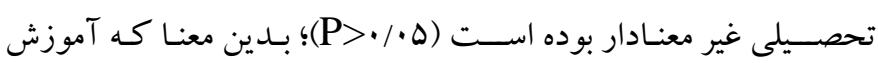

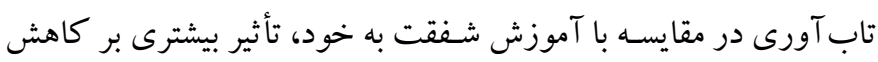

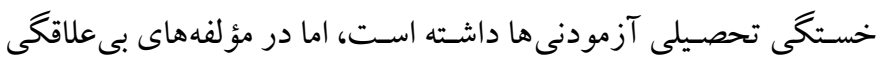

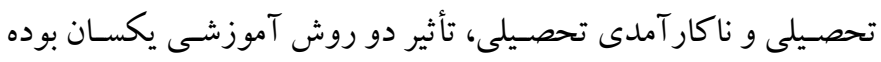

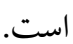


افســردگىى، كيفيت زندگىى، و مؤلفههاى آن در دانش آموزان افســـده؛

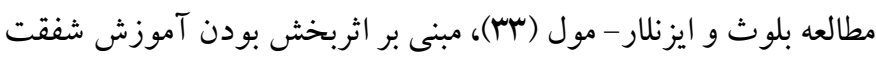

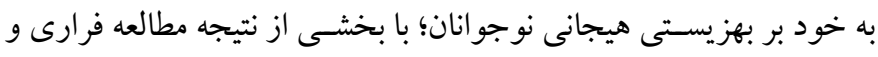

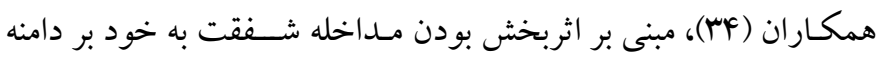

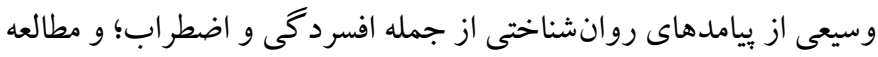

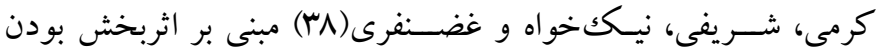
آموزش شفقت به خود بر كاهش فرسودگى تحصيلى، همسو است.

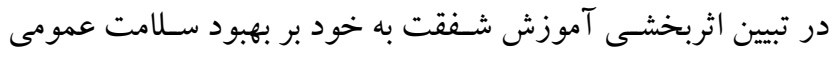

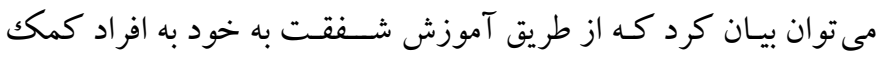

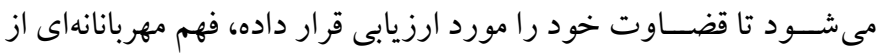

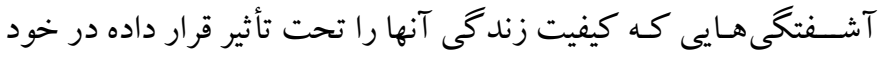
ايجاد كنند، و به صورت هوشيارانه احساسات و افكار خود را بيذيرند و

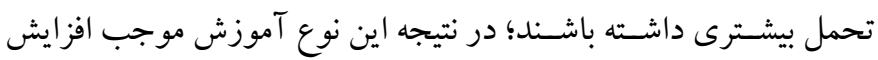

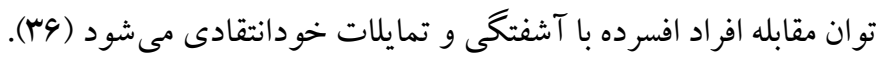

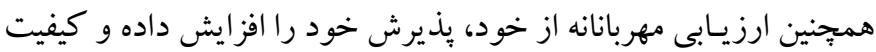
روابط بينفردى را بهتر مى كند و ميل افراد براى بهبودى و تحول مثبت را

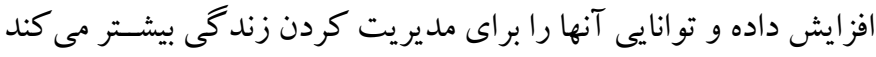
و در نتيجه از اين طريق مى تواند موجب افزايش ســلامت روانى در افراد

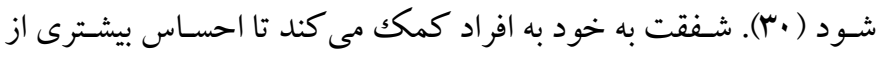

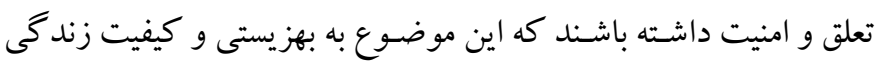
بهتر و در نتيجه سلامت عمومى بالاتر، منجر مىشود (YN). شفقت به خود باعث مى شـود افراد ترس كمترى از شكســت داشته

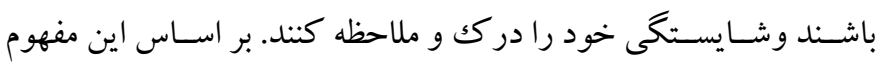
افرادى كه شفقت به خود بالايى دارند شكستها و كامنايافتخى هايى كه ونه

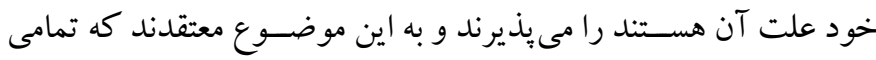
انسـانها نيز مى تو انند دجار لغزش و اشـتباهات شـوند؛ بنابر اين افرادى كه

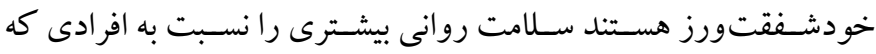
خودشفقتورزى كمترى دارند، تجربه مى كنند (N).

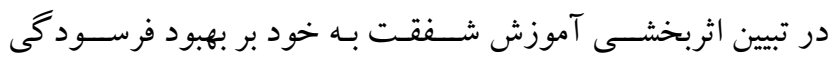
تحصـيلى مى توان بيان كرد شـفقت به خود با افزايش ارتباط اجتماعى و

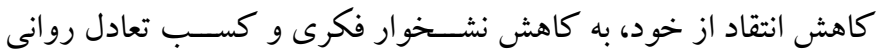
افر اد منجر مىشــود؛ بنـابر اين انعطـاف يذيرى در افكار و مهربانى با خود
دانش آموزان دختر؛ و مطـالعه لـانز (YD) مبنى بر اثربخش بودن مـداخلـه تاب آورى بر كاهش فرسودگى دانشجويان، همسو است.

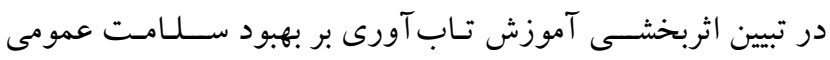

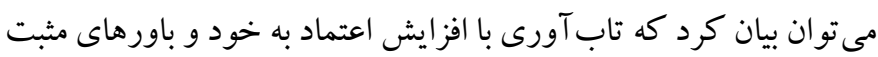
و كاهش احسـاس تنهايى و ناميدى باعث بهبود افسردگى مى شود (11).

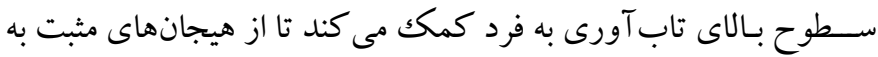

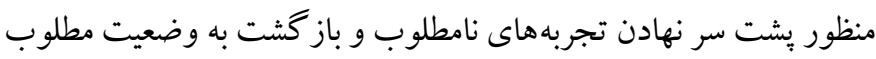

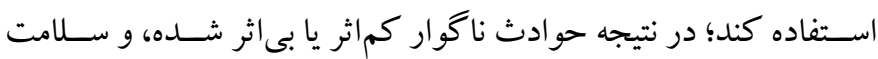

روان حفظ مى شود (Yr).

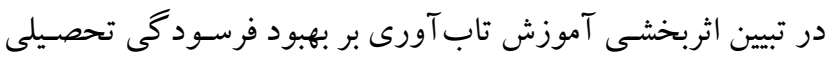

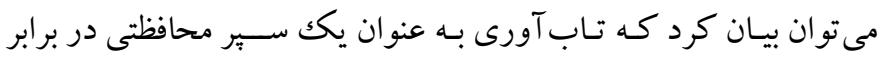
عوامـل تنش آور عمل مى كند و تأثير عوامل ايجاد كننده تنش را تعديل

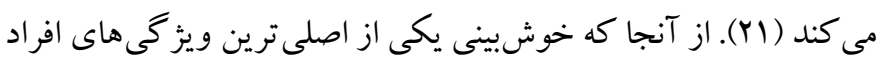

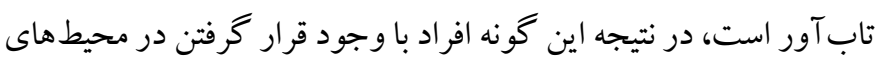

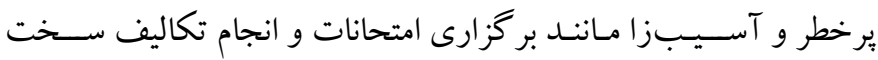

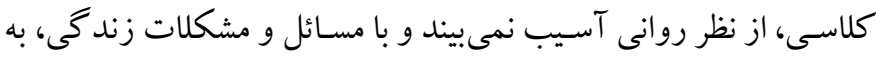

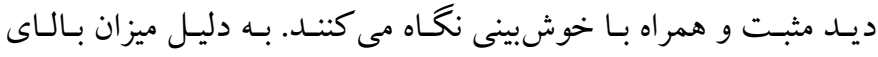

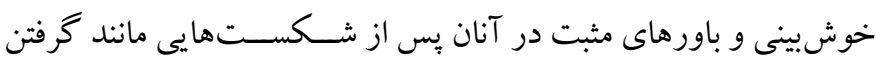

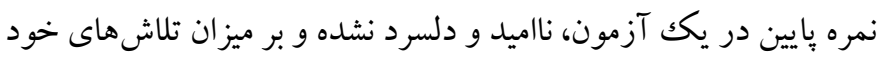

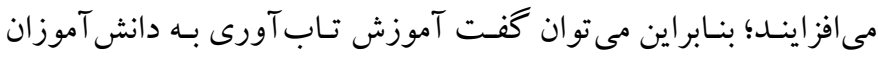

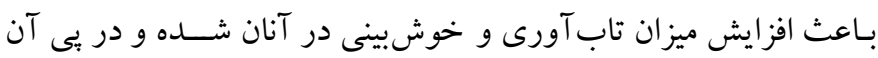
موجب كاهش خستلكى تحصيلى و بىعلاقكى تحصسيلى مىشـود (YY).

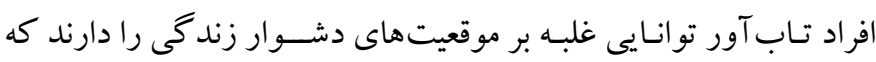
همين موضسوع باعث افزايش كارايى و كاهش فرسود گتى تحصيلى آنها

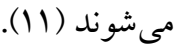
همجينين نتايج تحليل دادهها نشــان داد كه آموزش شـفقت به خود

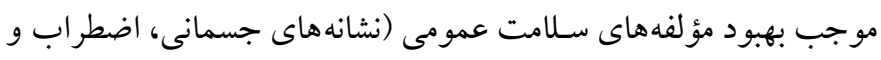

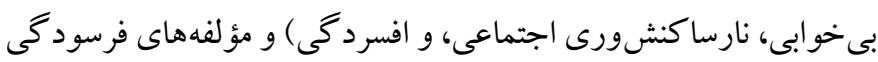

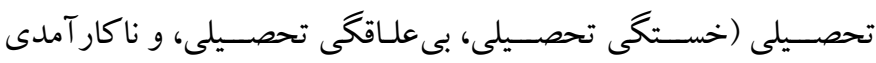

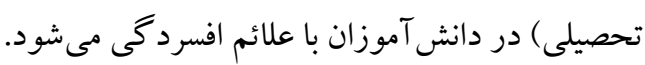

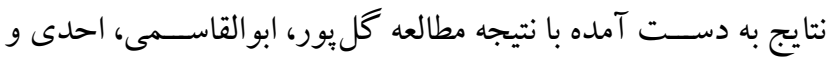

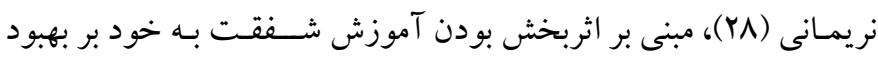


بـه عنو ان عـامل ايجاد كننده موفقيت بسـيار بالا در مدرسـهه و ســاير موقعيتهاى زندكى با وجود مصـائب و دشـوارىهاى محيطى دانسـت.

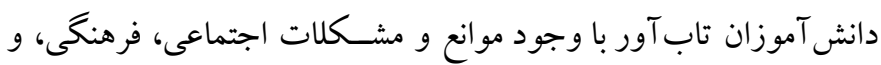
اقتصـادى در سـطح بالايى موفق مىشوند و كمتر نسبت به مدرسه و انجام

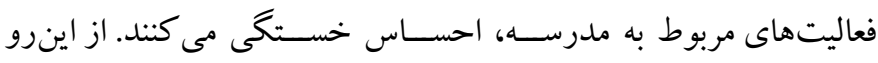

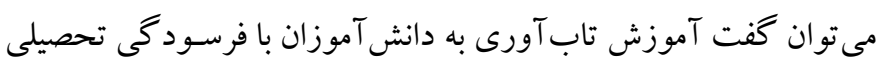
مى توانسـ ميزان تـابـآورى را در آنـان افزايش دهـد و بـا توجـه بـــ ويز گیىهايى كه براى افراد تابَآور ذكر شـد، مىتوان انتظار داشـت كه خستكى تحصيلى در اين افراد كاهش يابد. بـه طور كلى بر اســاس نتـايج اين مطالعه، آموزش هاى تابـآورى و شـفقت به خود از كارايى لازم براى بهبود سـلامت عمومى و فرسـودكى تحصسيلى دانش آموزان با علائم افسردگ

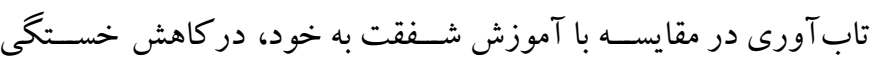
تحصــلى، مؤثرتر بوده اسـت. فر اهم نبودن شــر ايط براى اجراى مرحله بيخيرى، تقويت اثر هالهاى مربوط به يكى بودن مداخله كر با بثزوهشــر، وعدم بهرهمندى از يويايى گروه در فرايند آموزش به دليل شر ايط خاص تروس نو جوانـان با علائم افسـردكى، از محدوديت هاى اين بئوهش بود. بر اين اسـاس بيشــنهاد مى شــود كه در بثزوهشهاى بعدى، جهت بررسـى اثر ماند كارى اين آموزشها، دوره بيخيرى نيز در نظر كرفته شــود و مداخله توسط افرادى غير از يثزوهشكر انجام شود. در سطح به كار بسته يافته اي اين بزؤهش بر اى مشـاورانى كه در مدارس فعاليت دارند، داراى اهميت بالايى اســت. با توجه به اينكه آموزش تاب آورى در كاهش خســـى تحصـيلى، نسـبت به آموزش شفقت به خود، مؤثرتر بوده است، در نتيجه بيشنهاد مى شود از اين روش براى كاهش خستگى تحصيلى دانش آموزان با علائم افسـردكى، توسط روانشــاسـان و مشـاوران در مدارس اسـتفاده

ملاحظات اخلاقى

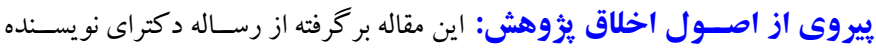

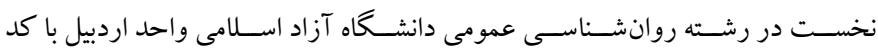

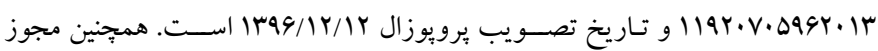
اجراى آن بر روى افراد نمونه از سـى اداره آموزش و يرورش شهـرستان بارس آباد در
موجب مى شـود كه افراد نسبت به خود، قضاوتى واقعبينانه داشته باشند و نارسايى هاى عملكرد خود را مورد تجزيه و تحليل قرار داده و تصميمات مناسب را براى رفع آنها در نظر كيرند. از سوى ديخر شناسايى نقاط قوت آنها موجب ارتقاى حرمت خود شـده و در عملكرد بعدى آنها، اثر بسيار

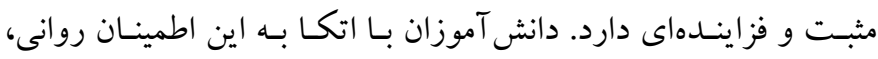
مى تو انند بر اعمال و رفتار خود تمركز بيشــرى داشـته و آن را به خوبى

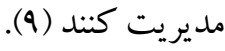

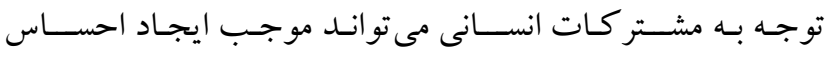
هم سرنوشتى با ديخران شود و از قضاوت هاى تند و افراطى نسبت به خود كه مختل كننده عملكرد مناسـب اسـت، جلو گيرى كند. كاهش انزواى روانى باعث مىشـود كه زمينه تعامل بيشـتر با ديخران و كسـب تجارب ياد گيرى متنوع براى افراد فراهم شـده و براى بيشـرفت تحصسيلى خود به طور مســتمر تلاش كنند و به ياد گيرند گان خودراهبر تبديل شـــوند (9). ذهن آكَاهى بـهـ عنوان يكى از مؤلفـهـــاى شــفــت به خود، مى تواند از فرســودكى تحصـيلى دانش آموزان افســـده بـازدارى كنــ. آموزش ذهن آكَاهى، بـا افزايش آكَاهى فرد از تجربيات لحظه حال و بر گرداندن توجـهـ بر نظـام شـــــاختى و وبردازش كـار آمـدتر اطلاعات، باعث كاهش نكر انى، بر انخيختخى فيزيولوزيكك، و تنيدكى مى شود (rV).

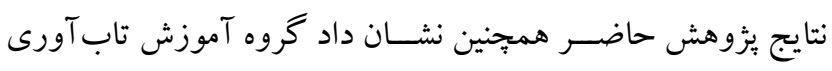
داراى ميانكين خستـى تحصـيلى كمترى در مقايسـه با كروه آموزش شـفقت به خود بود؛ بدين معنا كه آموزش تابآورى در كاهش خستخى تحصــيلى نسـبت به آموزش شــفقت به خود، مؤثرتر بوده اســت. در يثوهش هاى بيشـين، يثزوهشى كه با هدف مقايسه اين دو روش آموزشى انجام شده باشد، يافت نشده است. در تبيين اثربخشسى بيشـتر آموزش تابَآورى در مقايسـه با آموزش شـفقت به خود، بر كاهش خستكى تحصسيلى مى توان كفت از آنجا كه دانش آموزان تاب آور، كمتر احسـاس ناميدى مى كنند و از اين مهارت برخوردارند كه به يكك مشـكل به عنوان مسـئلهاى كه مىتوانند آن را كندو كاو كرده و تغيير دهند و در واقع يا به روشهاى ديخرى آن را حل كنند، در نتيجه همين موضسوع توان تحمل آنها در برابر مشـكلات بيشـتر شـده و سـبب بهبودانعطاف يذيرى، جشم انداز مثبت، و خوشبينى آنها به زندكى مى شـود (YY). بنابراين تاب آورى در محيط آموزشى را مىتوان 


\section{تضاد منافع: اين يزوهش براى نويسند كان هيج گونه تضاد منافعى نداشته است.}

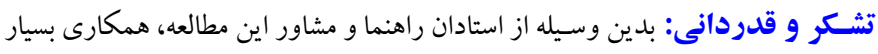

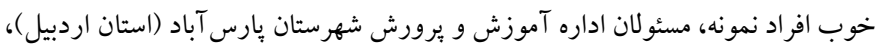
و كادر ادارى و مشاوران مدارس، تشكر و قدردانى مىشود.
سال 941ا صادر شده است. در اين يثوهش ملاحظات اخلاقى ماند رضايت كامل افر اد نمونه، رعايت اصل رازدارى، و محر مانه ماندن اطلاعات رعايت شده است. حامى مالىى: اين مطالعه بدون حامى مالى و در قالب رساله دكترا انجام شده است.

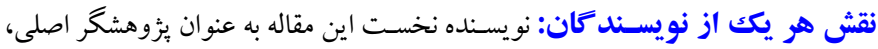
نو يسـند كان دوم و سوم به عنوان استادان راهنما، و نويسنده جهارم به عنوان استاد مشاور اين يُزوهش ، نقش داشتند. 


\section{References}

1. Mohammadi R, Nahang AA, Hoseini MA. The effectiveness of unified transdiagnostic therapy on self-concept and psychological disorder of the students with depression symptoms. J Child Ment Health. 2020; 6(4): 108-118. [Persian] Doi: 10.29252/ jcmh.6.4.11 [Link]

2. Kube T, Glombiewski JA, Gall J, Touissant L, Gärtner $\mathrm{T}$, Rief $\mathrm{W}$. How to modify persisting negative expectations in major depression? An experimental study comparing three strategies to inhibit cognitive immunization against novel positive experiences. $\mathbf{J}$ Affect Disord. 2019; 250: 231-240. Doi: 10.1016/ j.jad.2019.03.027 [Link]

3. Verma N, Jain M, Roy P. Assessment of Magnitude and Grades of Depression among Adolescents in Raipur City, India. Int. Res. J. Medical Sci. 2014; 2(5): 10-13. [Link]

4. Bevan Jones R, Thapar A, Stone Z, Thapar A, Jones I, Smith D, et al. Psychoeducational interventions in adolescent depression: a systematic review. Patient Educ Couns. 2018; 101(5): 804-816. Doi: 10. 1016/j. pec.2017.10.015 [Link]

5. Khorami Ghaziyani M, Abolghasemi A. The relationship between parental conflict resolution strategies and attachment styles with quality of life in adolescent girls with loneliness feeling. J Child Ment Health. 2020; 7(1): 1-14. [Persian] Doi: 10.29 252/ jcmh.7.1.2 [Link]

6. Haraldstad K, Christophersen KA, Eide H, Nativg GK, Helseth S. Health related quality of life in children and adolescents: reliability and validity of the Norwegian version of KIDSCREEN-52 questionnaire, a cross sectional study. Int J Nurs Stud. 2011; 48(5): 573-581. Doi: 10.1016/ j.ijnurst u.2010.10.001 [Link]

7. Barge-Schaapveld DQ, Nicolson NA, Berkhof J, Devries MW. Quality of life in depression: Daily life determinants and variability. Psychiatry Res. 1999; 88(3): 173-189. Doi: 10.1016/S0165-1781 (99)000815 [Link]

8. Valiyan AM, Sodani M, Shiralinia K, Khojasteh MR. The effectiveness of behavioral activation therapy in reduction of depression symptoms, cognitivebehavioral avoidance and quality of life in students. Contemporary Psychology. 2017; 12(1): 73-84. [Persian] [Link]

9. Narimani M, Einy S, Tagavy R. Explaining students' academic burnout based on self-compassion and sense of coherence. J Child Ment Health. 2018; 5(1): 36-47. [Persian] [Link]
10. Zhang Y, Gan Y, Cham H. Perfectionism, academic burnout and engagement among Chinese college students. A structural equation modeling analysis. Pers Individ Dif. 2007; 43(6): 1529-1540. Doi: 10.10 16/j.paid.2007.04.010 [Link]

11. Kamalpour S, Azizzadeh-Forouzi M, Tirgary B. A Study of the Relationship between Resilience and Academic Burnout in Nursing Students. Strides in Development of Medical Education. 2017; 13(5): 476487. [Persian] [Link]

12. Smeds MR, Janko MR, Allen S, Amankwah K, Arnell T, Ansari P, Balters M, Hess D, Ferguson E, Jackson P, Kimbrough MK. Burnout and its relationship with Perceived stress, Self-efficacy, Depression, Social support, and Programmatic factors in general surgery residents. Am J Surg. 2020; 219(6): 907-912. Doi: 10.1016/j.amjsurg.2019.07.004 [Link]

13. Salmela-Aro K, Upadyaya K. Developmental trajectories of school burnout: Evidence from two longitudinal studies. Learning and Individual Differences. 2014; 36: 60-68. Doi:10.1016/j.lindif. 2014.10.016 [Link]

14. Park CL. Integrating positive psychology into healthrelated quality of life research. Qual Life Res. 2015; 24(7): 1645-1651. Doi: 10.1007/s11136-014-0889-z [Link]

15. Reshadi H, Golpayegani F, Bayat B, Majdian V. Effectiveness of group play therapy on resilience and self-control strategies in children of divorced parents. J Child Ment Health. 2020; 6(4): 63-73. [Persian] Doi: 10.29252/jcmh.6.4.7 [Link]

16. Walsh F. Family resilience: A developmental systems framework. Eur J Dev Psychol. 2016; 13(3): 313-324. Doi: 10.1080/17405629.2016.1154035 [Link]

17. Deblinger E, Pollio E, Runyon MK, Steer RA. Improvements in personal resiliency among youth who have completed trauma-focused cognitive behavioral therapy: A preliminary examination. Child abuse \& Neglect. 2017; 65: 132-139. Doi: 10.10 16/j. chiabu.2016.12.014 [Link]

18. Zamiri nejad S, Golzari M, Borjali A, Hojjat SK, Akaberi A. The comparison of effectiveness of group resilience training and group cognitive therapy on decreasing rate of depression in female students who live in dorm. J North Khorasan Univ Med Sci. 2012; 4(4): 631-638. [Persian] Doi: 10.29252 /jnkums.4. 4. 631 [Link]

19. Tang WK. Resilience and Self-Compassion Related with Achievement Emotions, Test Anxiety, Intolerance of Uncertainty, and Academic Achievement. 
Psychological Studies. 2019; 64(1): 92-102. Doi: 10.1007/s12646-019-00482-6 [Link]

20. Sünbül ZA, Güneri OY. The relationship between mindfulness and resilience: The mediating role of self compassion and emotion regulation in a sample of underprivileged Turkish adolescents. Personality and Individual Differences. 2019; 139: 337-342. Doi: 10.1016/j.paid.2018.12.009 [Link]

21. García-León MÁ, Pérez-Mármol JM, Gonzalez-Pérez R, del Carmen García-Ríos M, Peralta-Ramírez MI. Relationship between resilience and stress: Perceived stress, stressful life events, HPA axis response during a stressful task and hair cortisol. Physiol Behav. 2019; 202: 87-93. Doi:10.1016/j.physbeh.2019.02.001 [Link]

22. Friborg O, Hjemdal O, Rosenvinge JH, Martinussen M, Aslaksen PM, Flaten MA. Resilience as a moderator of pain and stress. J Psychosom Res. 2006; 61(2): 213-219. Doi: 10. 1016/j. jpsychores. 2005. 12.007 [Link]

23. Kamalpour S, Azizzadeh-Forouzi M, Tirgary B. A Study of the Relationship between Resilience and Academic Burnout in Nursing Students. Strides in Development of Medical Education. 2017; 13(5):47687. [Link]

24. Yaghoobi A, Bakhtyari M. The effect of resiliency training on burnout in high school female students. Research in School and Virtual Learning. 2016; 4(13): 45-56. [Persian] [Link]

25. Lanz JJ. Evidence-Based Resilience Intervention for Nursing Students: a Randomized Controlled. Pilot Trial. Int J Appl Posit Psychol. 2020; 5(3):217-230. Doi: 10.1007/s41042-020-00034-8 [Link]

26. Neff K. Self-compassion: An alternative conceptualization of a healthy attitude toward oneself. Self and Identity. 2010; 2(2): 85-101. Doi: 10.10 80/ 15298860309032 [Link]

27. Petersen LE. Self-compassion and self-protection strategies: The impact of self-compassion on the use of self-handicapping and sandbagging. Pers Individ Dif. 2014; 56: 133-138. Doi: 10.1016/ j.paid. 2013. 08.036 [Link]

28. Golpour R, Abolghasemi A, Ahadi B, Narimani M. The effectiveness of cognitive self-compassion training and emotion-focused therapy on quality of life with depression disorder. Journal of Clinical Psychology. 2014; 6(1): 53-64. [Persian] Doi: 10.22075/jcp.2017.2154 [Link]

29. Lathren C, Bluth K, Park J. Adolescent selfcompassion moderates the relationship between perceived stress and internalizing symptoms. Pers
Individ Dif. 2019; 143: 36-41. Doi: 10.1016/j. paid. 2019.02.008 [Link]

30. Homan KJ. Self-compassion and psychological wellbeing in older adults. J Adult Dev. 2016; 23(2): 111119. Doi: $10.1007 / \mathrm{s} 10804-016-9227-8$ [Link]

31. Ross ND, Kaminski PL, Herrington R. From childhood emotional maltreatment to depressive symptoms in adulthood: the roles of self-compassion and shame. Child Abuse Negl. 2019; 92: 32-42. Doi: 10.1016/j.chiabu.2019.03.016 [Link]

32. Mathad MD, Rajesh SK, Pradhan B. Spiritual wellbeing and its relationship with mindfulness, selfcompassion and satisfaction with life in baccalaureate nursing students: a correlation study. J Relig Health. 2019; 58(2): 554-565. Doi: 10.1007/s10943-0170532-8 [Link]

33. Bluth K, Eisenlohr-Moul TA. Response to a mindful self-compassion intervention in teens: A withinperson association of mindfulness, self-compassion, and emotional well-being outcomes. J Adolesc. 2017; 57: 108-118. Doi: 10.1016/j.adolescence.2017.04.001 [Link]

34. Ferrari M, Hunt C, Harrysunker A, Abbott MJ, Beath AP, Einstein DA. Self-compassion interventions and psychosocial outcomes: a meta-analysis of RCTs. Mindfulness. 2019; 10(8): 1455-1473. Doi: 10.1007 /s12671-019-01134-6 [Link]

35. Phillips WJ. Future-outlook mediates the association between self-compassion and well-being. Pers Individ Dif. 2018; 135: 143-148. Doi: 10.1016/J. PAID. 2018. 07.006 [Link]

36. Gilbert P, Procter S. Compassionate mind training for people with high shame and self-criticism: Overview and pilot study of a group therapy approach. Clinical Psychology \& Psychotherapy: An International Journal of Theory \& Practice. 2006; 13(6): 353-379. Doi: 10.1002/cpp.507 [Link]

37. Hwang YS, Medvedev ON, Krägeloh C, Hand K, Noh JE, Singh NN. The role of dispositional mindfulness and self-compassion in educator stress. Mindfulness. 2019; 10(8): 1692-1702. Doi: 10.1007/s12671-01901183-x [Link]

38. Karami R, sharifi T, Nikkhah M, Ghazanfari A. The Effect of Educating Cognitive Self-compassion on Academic Well-being. SCI J Educ Strategy Med Sci. 2018; 11(4): 17-22. [Persian] Doi: 10.29252 /edcb mj.11. 04.03 [Link]

39. Birleson P. The validity of depressive disorder in childhood and the development of a self-rating scale: a research report. J Child Psychol Psychiatry. 1981; 
22(1): 73-88. Doi: 10.1111/j.1469-7610.1981. tb00 533.x [Link]

40. Birleson P, Hudson I, Buchanan DG, Wolff S. Clinical evaluation of a self-rating scale for depressive disorder in childhood (Depression Self-Rating Scale). J Child Psychol Psychiatry. 1987; 28(1): 43-60. Doi: 10.1111/j.1469-7610.1987.tb00651.x [Link]

41. Mokhtarnia I, Habibi M, Kholghi H, Mohammadi E, Kalantari F. The study of psychometric properties of the self-rating depression scale for children and adolescents. Journal of Rooyesh-e-Ravanshenasi. 2018; 7 (4): 1-22. [Persian] [Link]

42. Goldberg DP, Hillier VF. A scaled version of the General Health Questionnaire. Psychol Med. 1979; 9(1): 139-145. Doi: 10.1017/S0033291700021644 [Link]

43. Mahdavi M, Behpajooh A, Hasanzadeh S, Sajadi Anari SS. The effectiveness of hope therapy on promoting mental health and reducing academic burnout in high school students at risk for academic burn-out. J Child Ment Health. 2020; 7(1): 128-140. [Persian] Doi: 10.29252/jcmh. 7.1. 12 [Link]
44. Yekanizad A. Comparison mental health, social phobia and psychological distress of children under the care of the welfare organization and children under the care of the family. J Child Ment Health. 2018; 4(4): 140-151. [Persian] [Link]

45. Broadbear JT, Jin G, Bierma TJ. Critical thinking dispositions among undergraduate students during their introductory health education course. Health Educ. 2005; 37(1): 8-15. [Link]

46. Moosavi Nasab SMH, Taghavi M. Effect of stress appraisal and coping strategies on mental health. Hormozgan Med J. 2007; 11(1): 83-90. [Persian] [Link]

47. Bresó E, Salanova M, Schaufeli WB. In search of the "third dimension" of burnout: Efficacy or inefficacy? Applied Psychology. 2007; 56 (3): 460-472. Doi: 10.1111/j.1464-0597.2007.00290.x [Link]

48. Ezatpour EE, Delkhosh V, Rahmani S, Ezatpour S. Investigate of the Relationship between Mental Health and Academic Burnout of Students at the Farhangian University. Shenakht Journal of Psychology \& Psychiatry. 2018; 5(4): 1-13. [Persian] Doi: 10. 29252 /shenakht.5.4.1 [Link] 